\title{
رؤيةُ العالَّم بوصفها أداةً إجرائية لمقاربة الحداثة
}
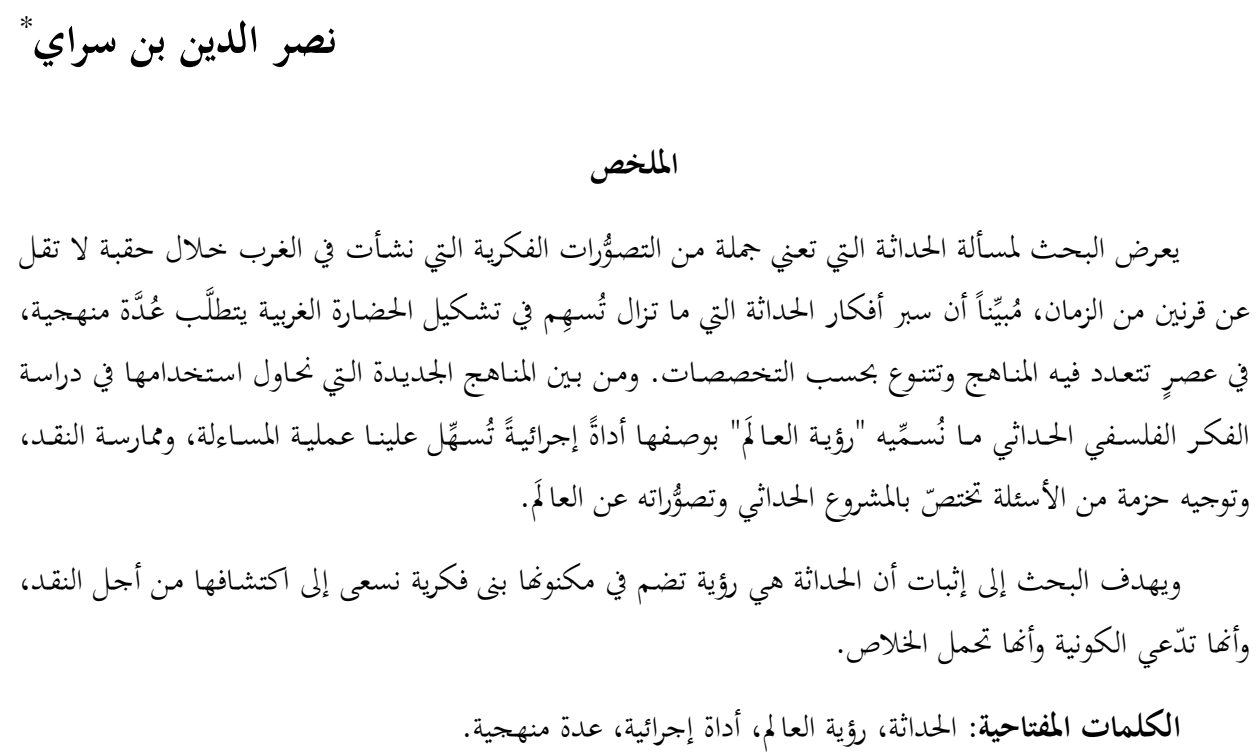

\section{Worldview as a Procedural Instrument to Approach Modernity}

\section{Nasruddin Ben Serai}

\begin{abstract}
The paper deals with the issue of modernity which is known to have certain intellectual perceptions that has developed in the West during two centuries or more. Modernity continues to shape Western civilization; the exploration of its ideas requires certain methodological equipment, especially in this age of multiple approaches and specialties. Worldview is one of the new approaches that is being used in the study of modern philosophical thought. Worldview is considered as a procedural instrument that facilitates raising questions and practicing criticism of modernity project and its perception of the world.

The purpose of the study is to prove that modernity is a worldview that includes certain intellectual structures to be discovered and criticized, in order to deal with modernity's claims of universality and its possibility of providing salvation.

Key words: Modernity, Worldview, Procedural instrument, Methodological equipment.

$$
\begin{aligned}
& \text { * دكتـوراه فلسـفة القـيم وابسـتمولوجية العلـوم الإنسـانية، جامعـة لمـين دبـاغين، سـطيف بـ البريـــ الإلكـتروبي: } \\
& \text { benserai20@gmail.com }
\end{aligned}
$$

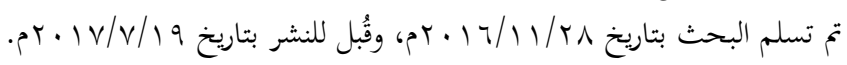




\section{مقدمة:}

إن تعدُّد المنـاهج والقراءات الفكرية والفلسفية يعني بالضـرورة تعلُّد منـاحي القضايا المطروحة في الفكر الفلسفي. ومن أكثر أنواع القراءات تعقيداً تلك التي ينماز موضوعها

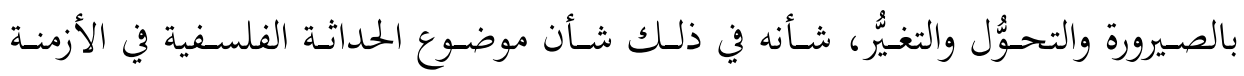

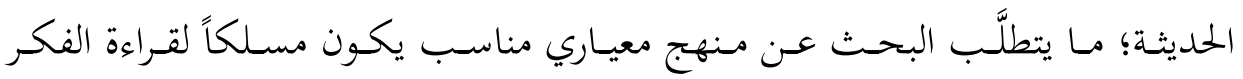
الحداثي الغربي.

وهنا يظهر الاختلاف جلياً بين الباحثين الذين يسعون إلى تعرُّف كُنْه الحقبة الفكرية

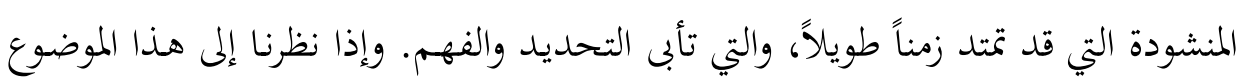

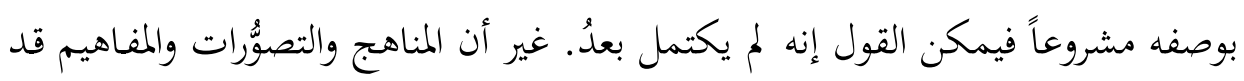

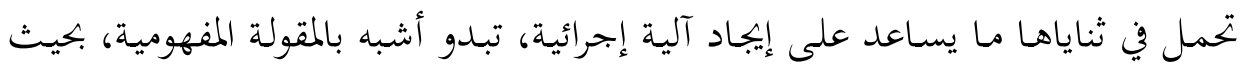

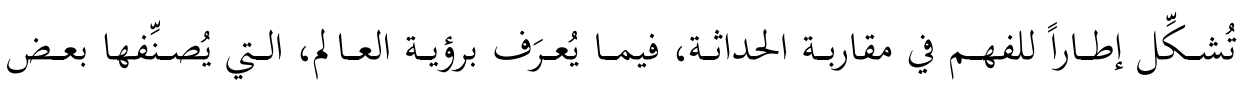

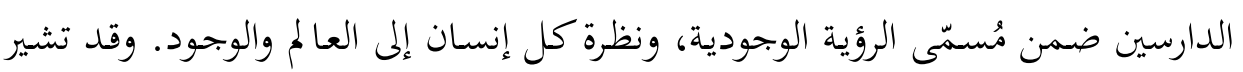

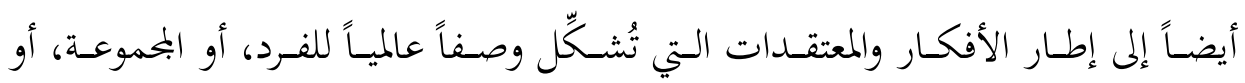

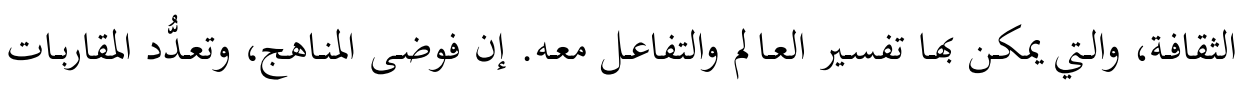

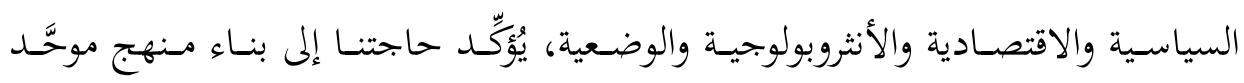

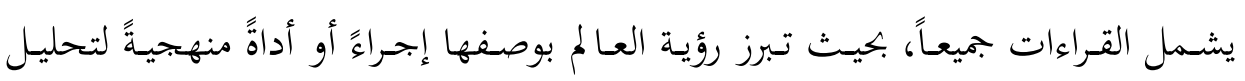
الفكر الحداثي.

فعن طريق هـذه الأداة ومـا تنطوي عليه مـن إِحكام المسـاءلة، وفن صياغة الأسئلة

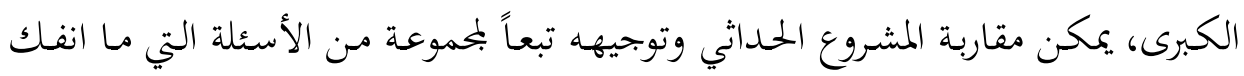

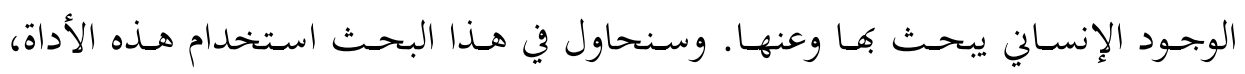
ولفت الانتباه إليها، مُبرِين أهمية الأسئلة الكبرى التي تحاول رؤية العالم الإجابة عنها.

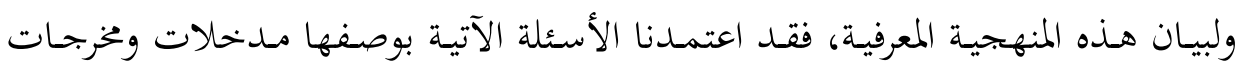




$$
\text { - ما المقصود برؤية العالم؟؟ }
$$

- ما مسوغات استخدام هذا الدالّ المفهومي (رؤية العالمَ في مقاربة الحداثة)؟ - ما ضوابط التساؤلات الفلسفية في مقاربة مفهوم "الحداثة" بوصفها رؤية للعالم؟؟ وتتأكَّد قيمة هذا البحث المنهجي بعد ما أصبح التفكير الفلسفي المعاصر يُمِّل أحد منظورين: بناء رؤية وجودية جديدة للعالم، أو إصلاح رؤية قديمة، لم تعد فاعلة في الحياة

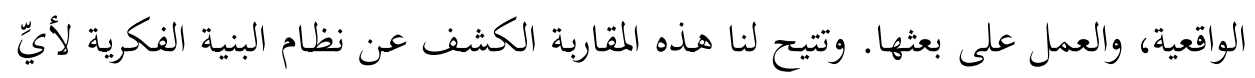

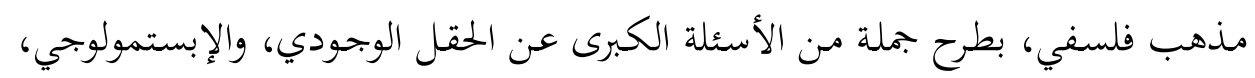
والأكسيولوجي.

\section{أولاً: تعريف مصطلح "رؤية العالم" لغوياً وفلسفياً}

\section{ا ـ الدلالة المعجمية اللغوية لمصطلح "رؤية العالم":}

يجفل مصطلح "رؤية العالم" في المعاجم اللغوية بمعانٍ ودلالات تكشف عن الثراء

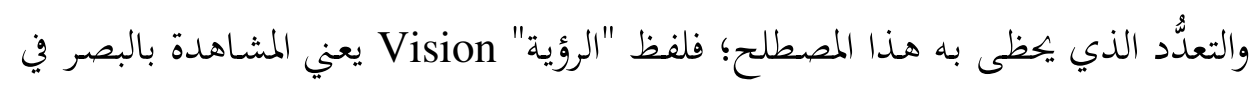

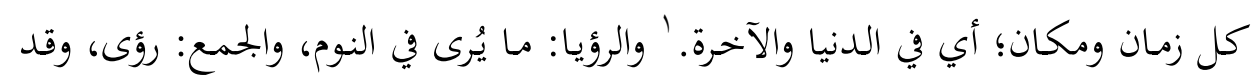

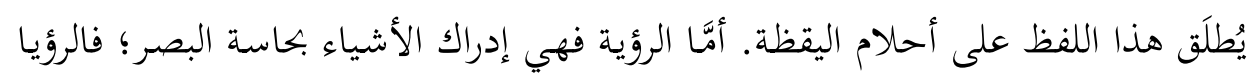

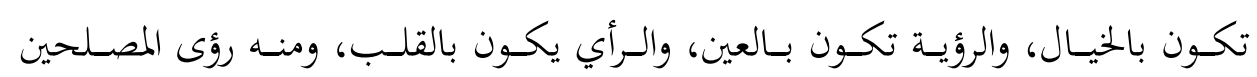
الاجتماعيين.

والمشاهدة بالبصر قد يراد بها العلم بحازاً، وإذا رافقتها الإحاطة سِيّيت إدراكاً. وتُطلَق

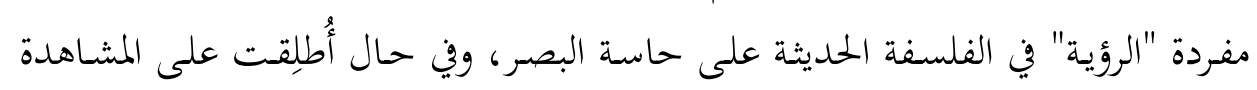

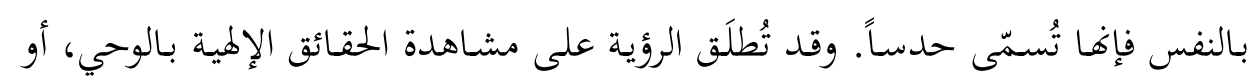
الإدراك بالوهم، أو المشاهدة بالخيال. وتنص نظرية الفيلسوف ماليرانس على أن الإنسان

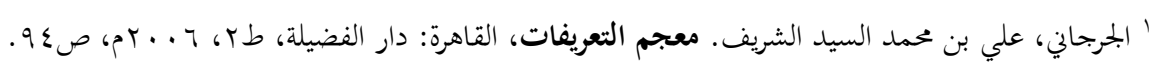

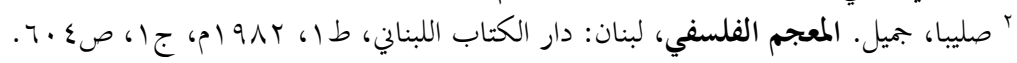




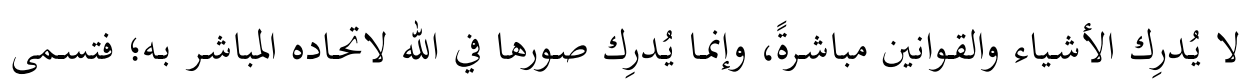
الرؤية في الله: Vision en Dieu وقد تحمل الرؤية معنى التصوُّر Concept في الفرنسية؛ فتصوُّر الشيءٍ يعني تخيُّله،

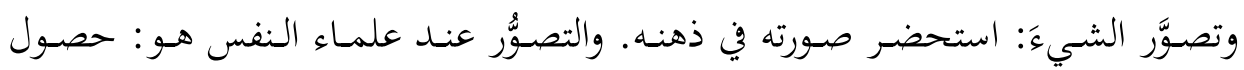

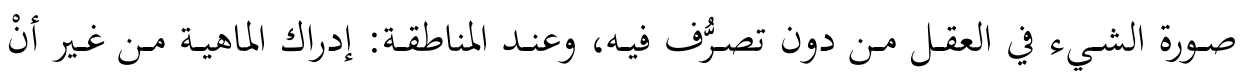
يُجكَم عليها بنفي أو إثبات (كما هو عند الجرجائي في تعريفاته). وهو يفيد أيضاً معنى

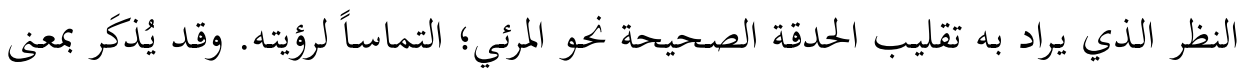

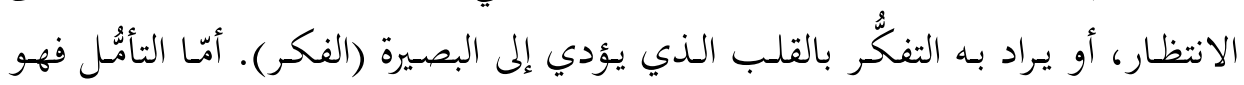

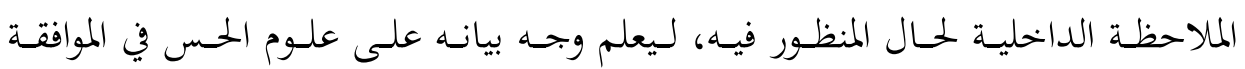

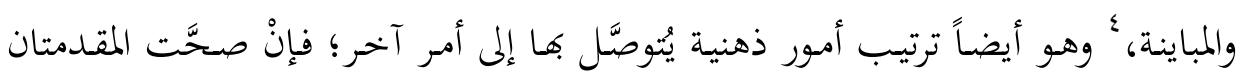

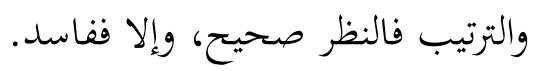

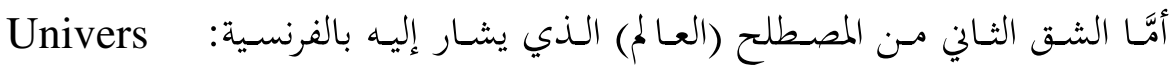

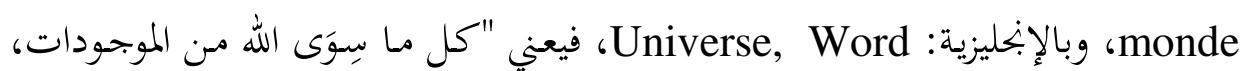

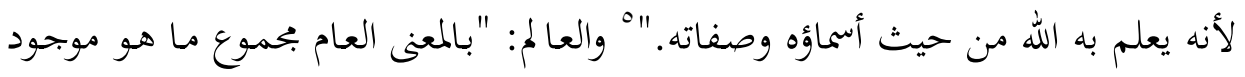

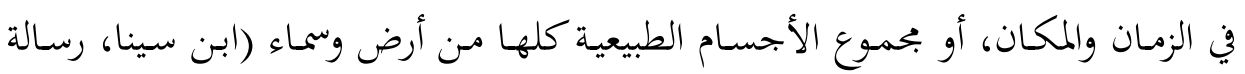

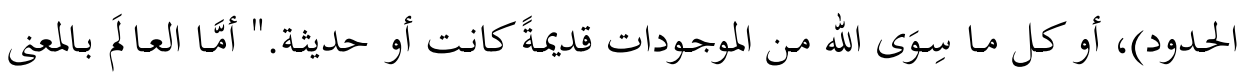
الخاص فيُطلَق على جملة الموجودات من جنس واحد، مثل قول ابن سينا: "يقال عالم الم

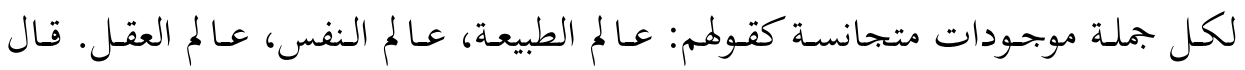

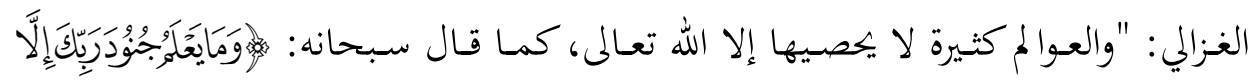

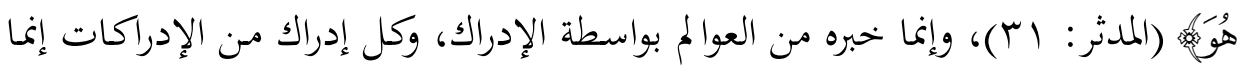

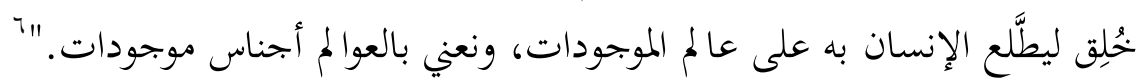

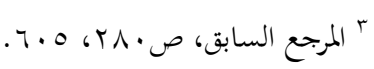

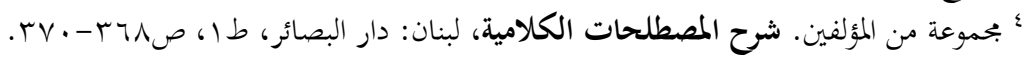

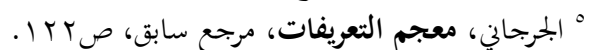

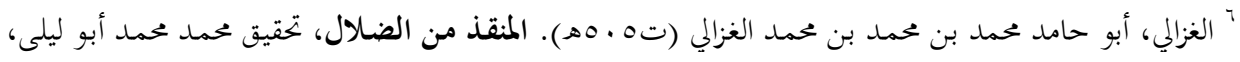

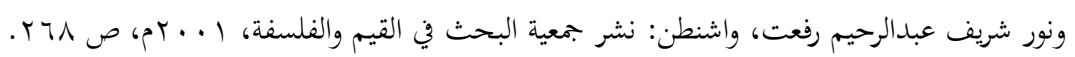




\section{ب. ب. الدلالة الفلسفية لمصطلح "رؤية العالم":}

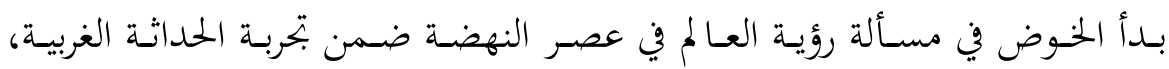

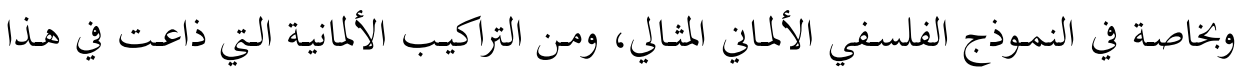

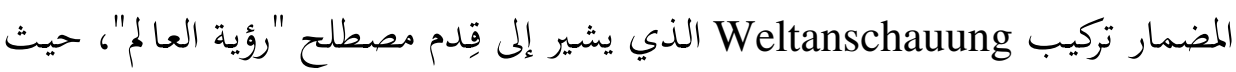

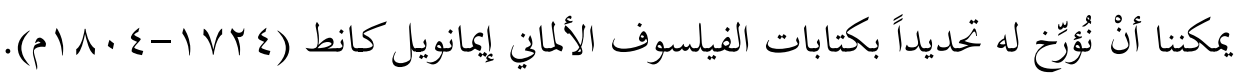

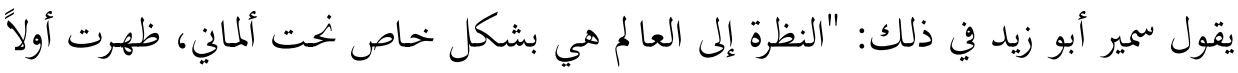

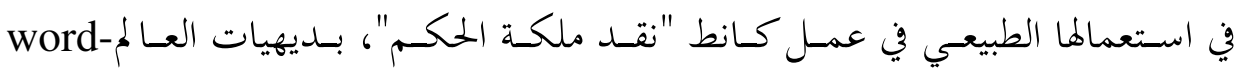
لمبن intuition

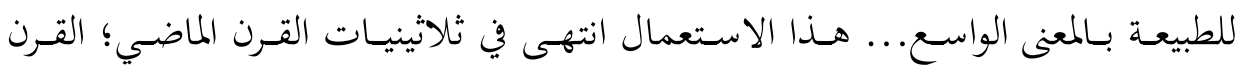

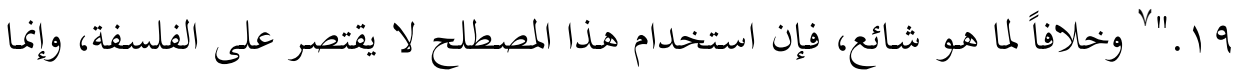

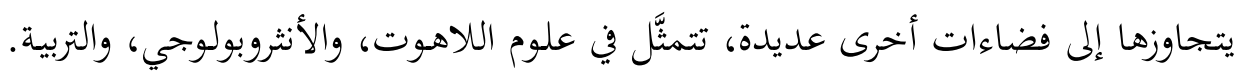

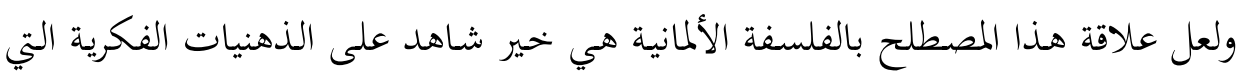

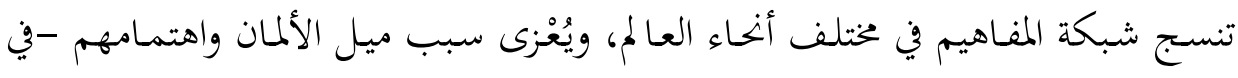
بعضه- ببناء الأنساق إلى غياب ألمانيا عن ميدان السباق الأوروبي نحو السيطرة العالمية.

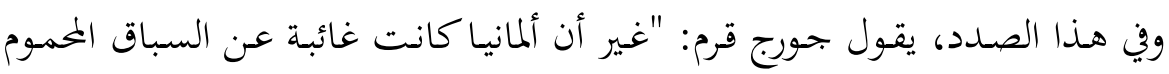

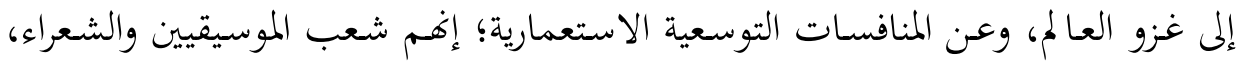

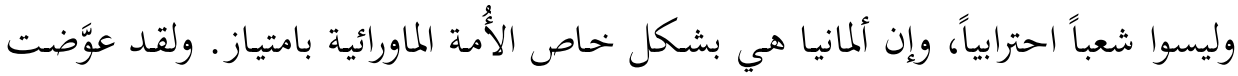

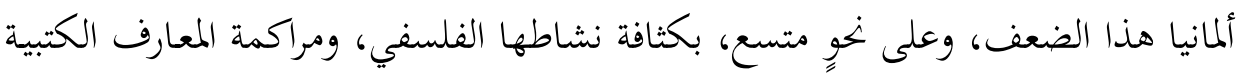

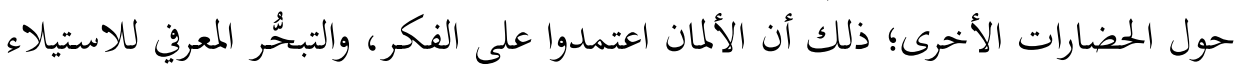

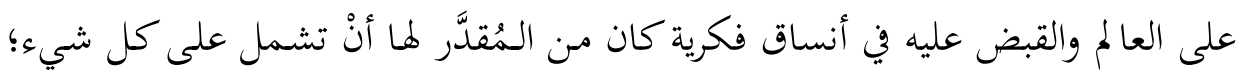

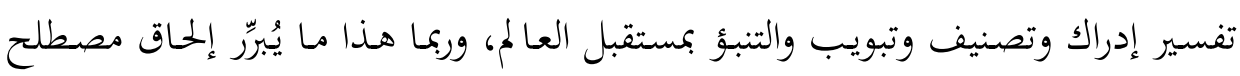

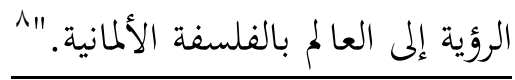

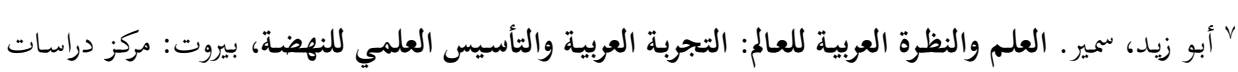

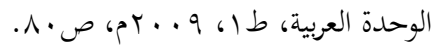

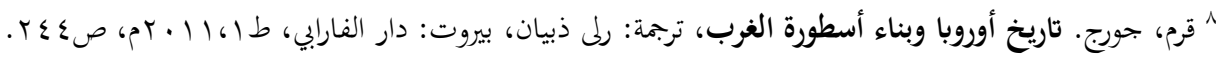




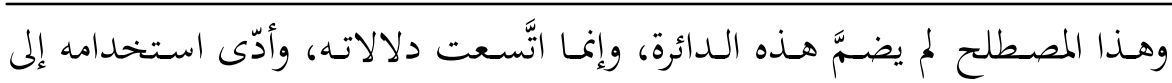

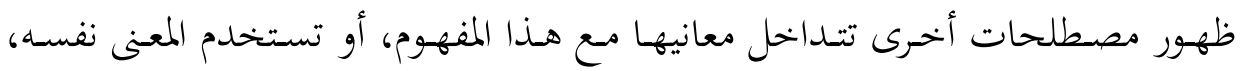

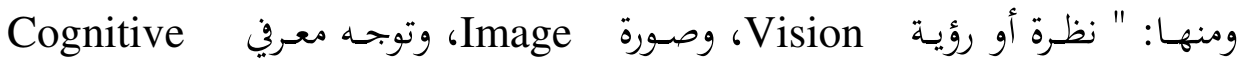

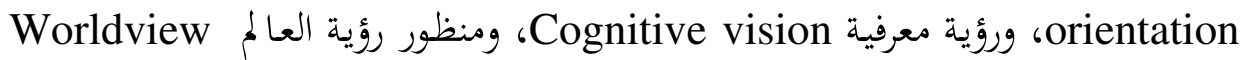

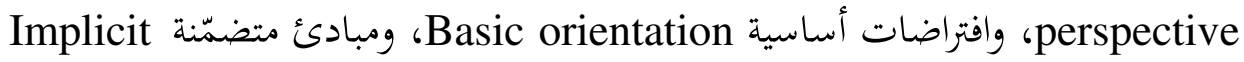

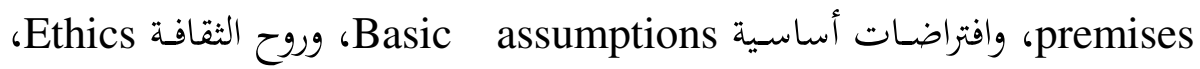

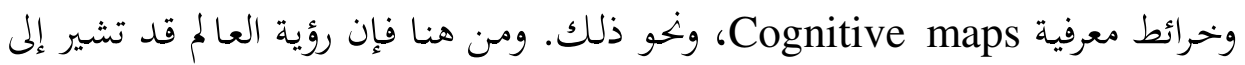

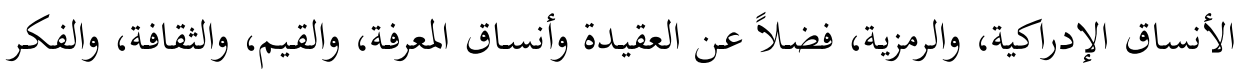
والتفكير. " الأساق الإن

والغرض مـن إيراد هـذه التقنيـة النقدية هـو ربط رؤيـة العـالم (مصطلحاً، ومفهومـاً)

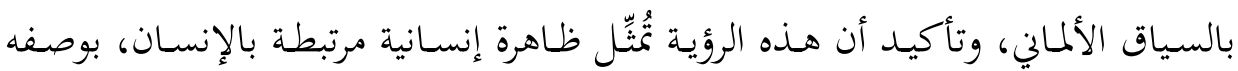

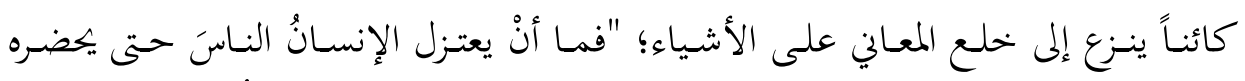

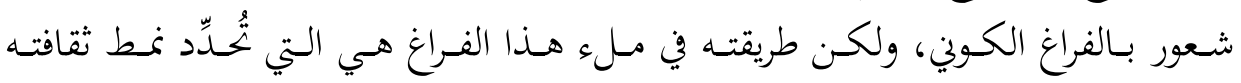
وحضارته؛ أي جميع الخصائص الداخلية والخارجية لوظيفته التاريخية، وانعدام الفراغ الكوني فئي

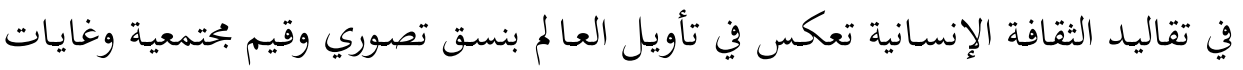

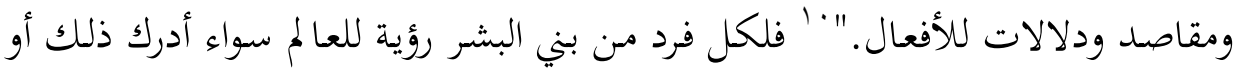

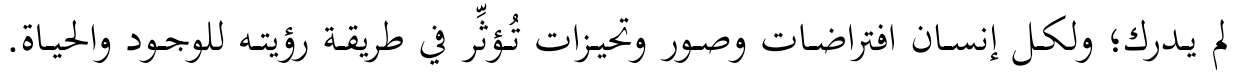

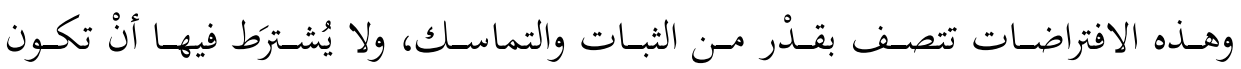

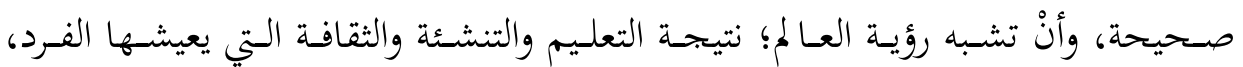
ويحدث هذا التشكُّل بصورة تدريجية بطيئة تشبه عملية الامتصاص الأسموزي. 'ل ولتصوُّر رؤية العالم أهمية تتمثَّل في "معالجة مشكلة المعنى لارتباطه الوثيق بها -إذكل

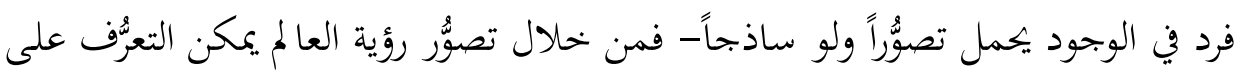

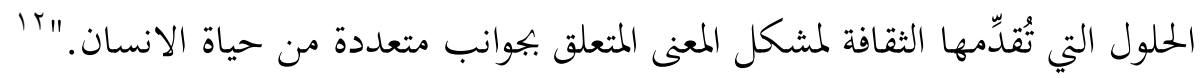

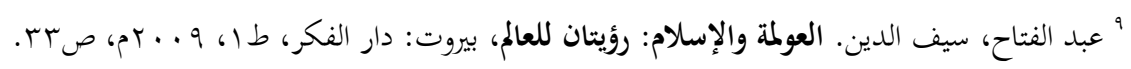

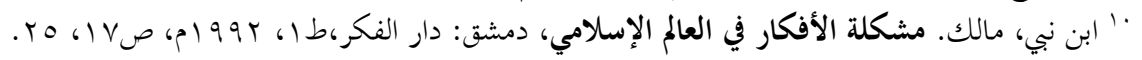
${ }^{11} \mathrm{http}: / / \mathrm{www}$. christianworldview.net/

rr عبد الفتاح، العولمة والإسلام: رؤيتان للعالم، مرجع سابق، صابـ. 


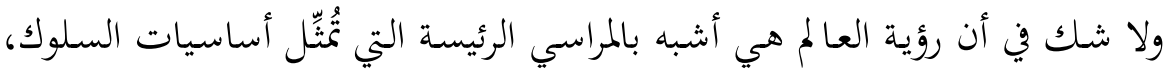

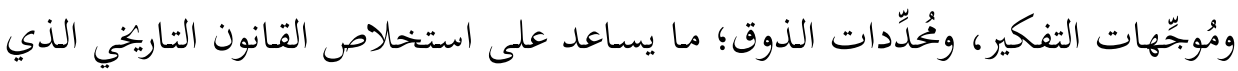
يتبدّى في ثبات الرؤية نحو العالم خهلال مسارات التاريخ الثقافي للإنسـان، أو التسليم

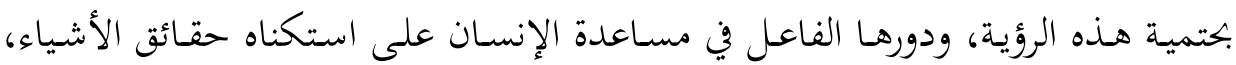

$$
\text { ومواجهة صراعات القُوى بمزيد من الثبات والشجاعة. }
$$

ورؤية العالم مصطلح فلسفي حديث يراد به النظر إلى العالم نظرة شاملة، بما في

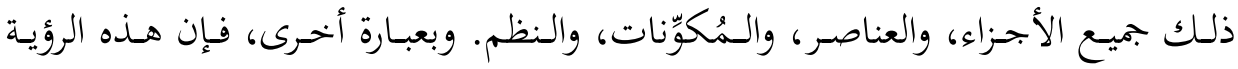

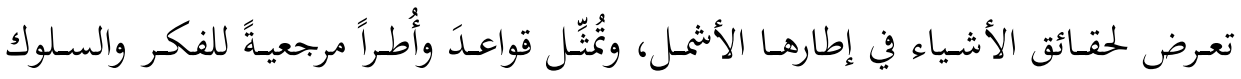

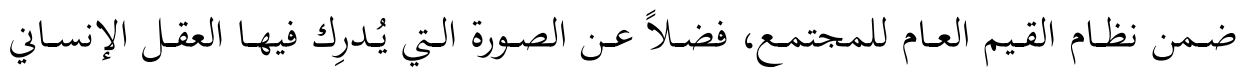

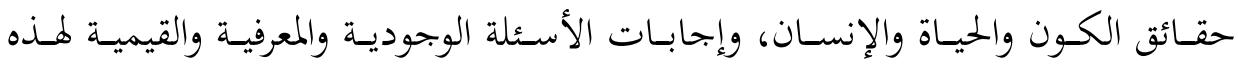
الحقائق.

ويتبيَّن مُّاّ سبق أن هذا المصطلح يضم المفردات الكبرى الناظمة للوجود الكلي التي

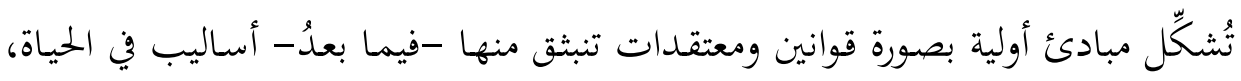
ومقاصد في السلوك، ويمكن بها إثراء هذه الأساليب والسلوكات، وإعطائها المعنى المراد.

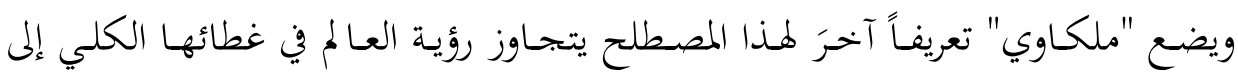
مستوى الفعل فيه، ضمن ثلاثة مستويات مترابطة:

" أ. رؤية العالم أولاً: تصوُر ذهني للعوا لمُ الطبيعية والاجتماعية والنفسية، بحيث تبدو

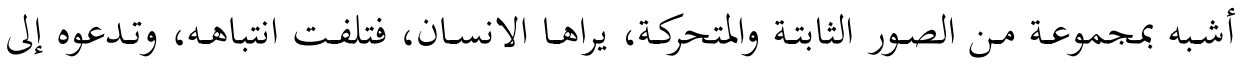
التفكُّر والتأمُّل بقصد الفهم والإدراك. مجن.

ب. رؤية العالم ثانياً: موقف من العالم، أو حالة نفسية تعتري الإنسان، فتستدعي

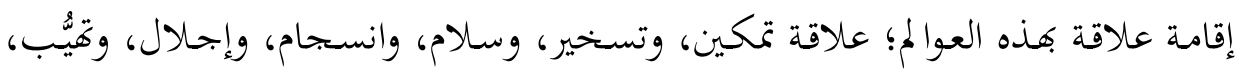




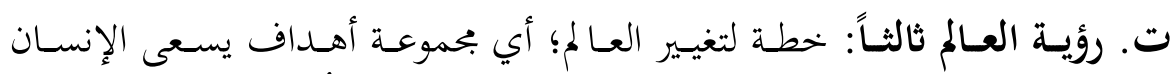

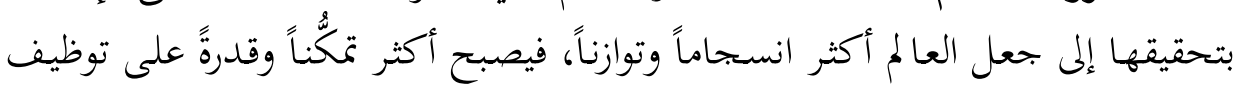

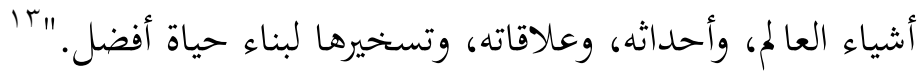
ومن المُملاحَظ أن المفهوم الثاني لرؤية العالم يتضمن المعيارية؛ ما يعني أنه لا يقتصر

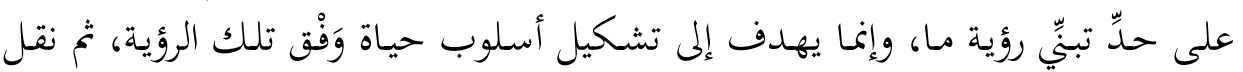

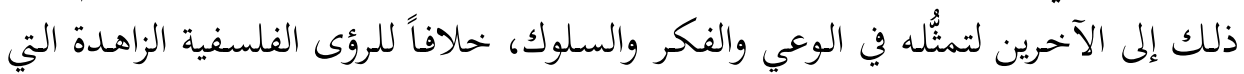

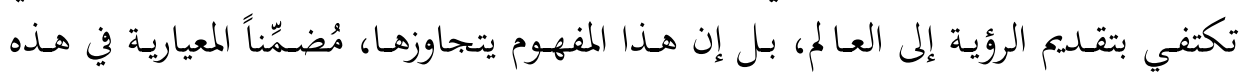

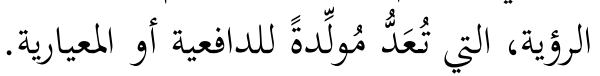

ثانياً: الدلالة الحقلية لمصطلح "رؤية العالم"

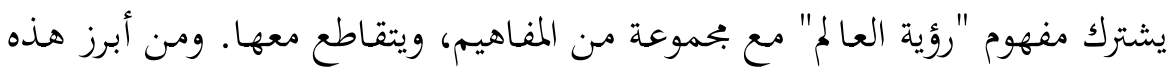

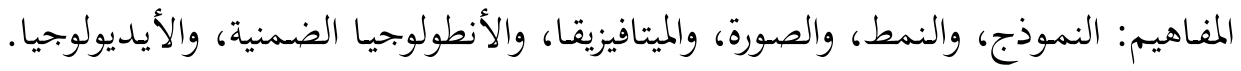
وسنحاول فيما يأتي تبيان حدود علاقة مفهوم الدراسة بالنموذج المعريف، والميتافيزيقا:

\section{ا ـ الرؤية إلى العالم والنموذج المعرفي:}

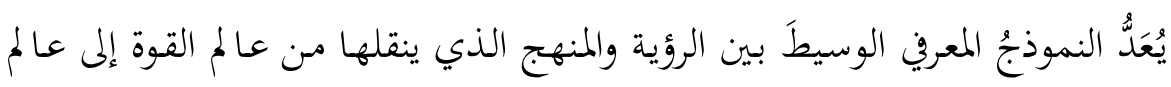

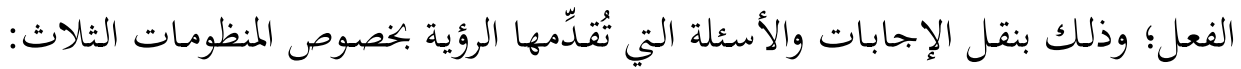

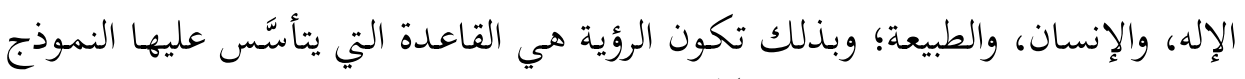

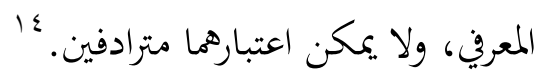

\section{Y ب الرؤية إلى العالم والميتافيزيقا:}

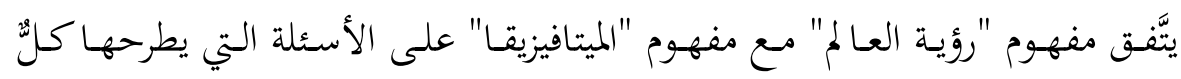

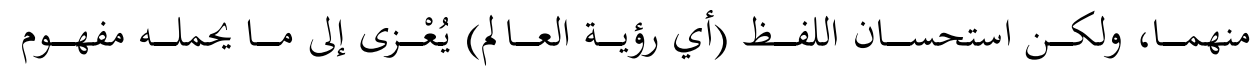

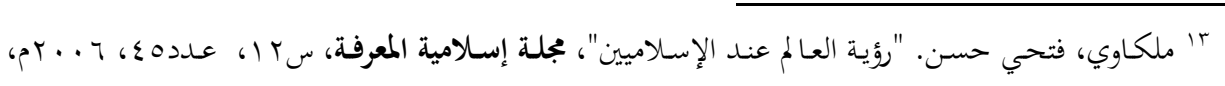
صه- ع ז.

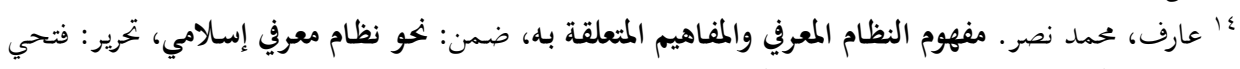

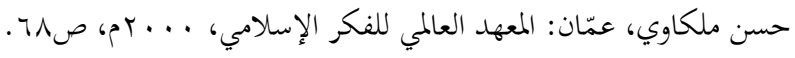




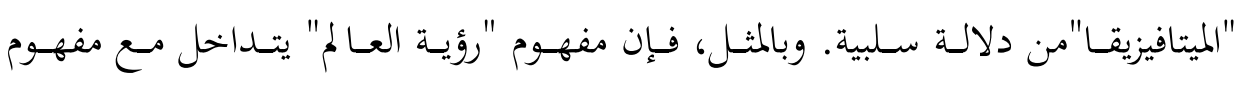

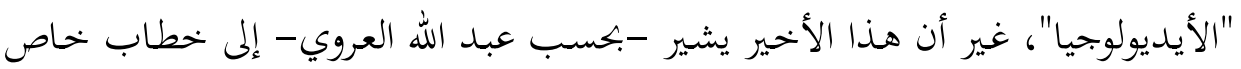

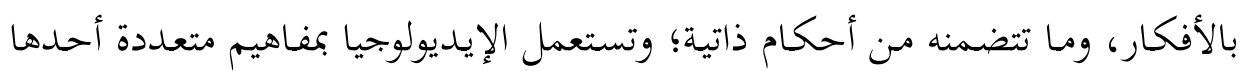

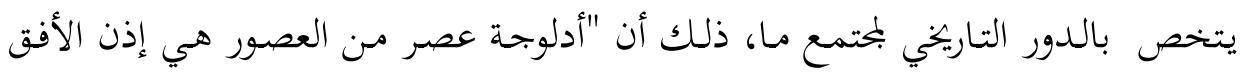
الذهي الذي كان يحد فكر إنسان ذلك العصر.

ب. بـ لماذا الوؤية إلى العالم؟ أو نحو بيان الداعي من استدعاء هذا الدال الدال المفهومي

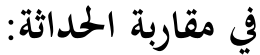

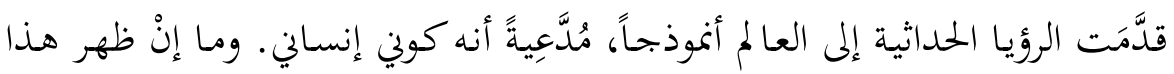

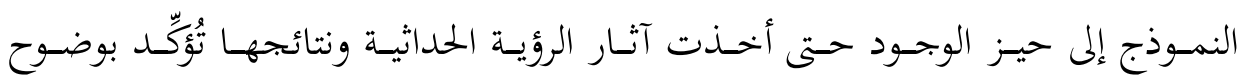

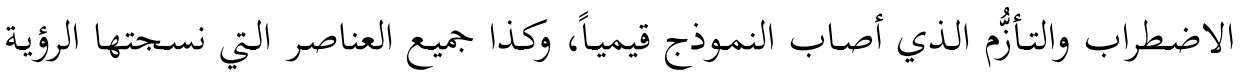

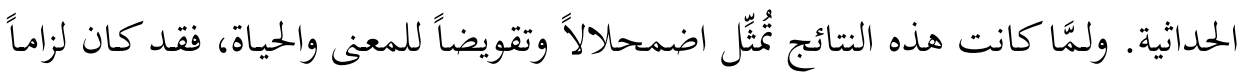

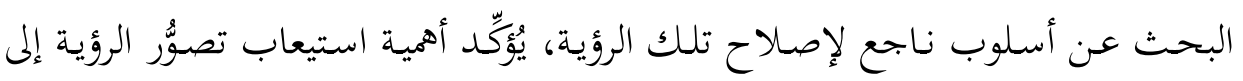

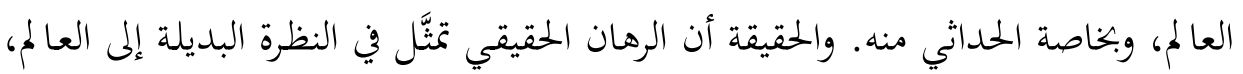

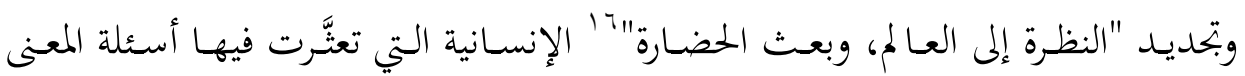

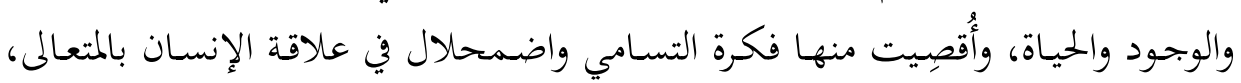

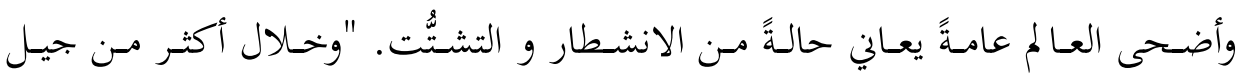

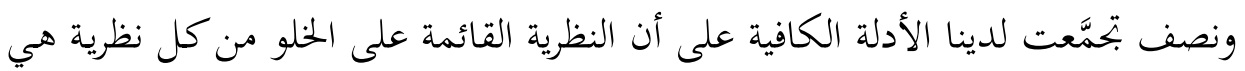

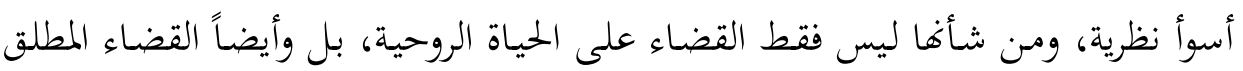

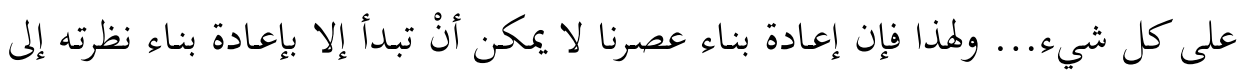

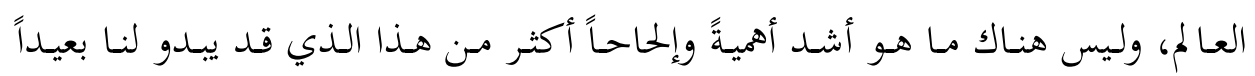

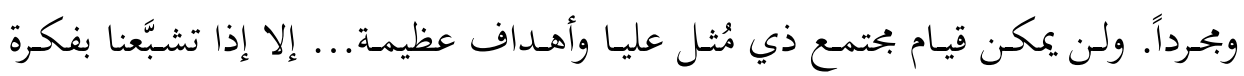

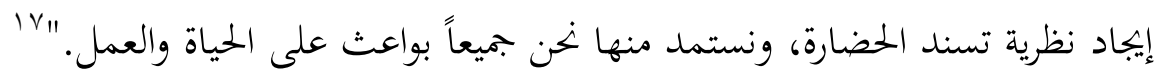

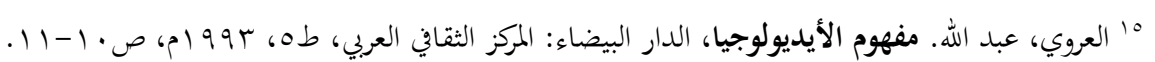
17 "شفايتزر، ألبرت. فلسفة الحضارة، ترجمة: عبد الرممن بدوي، مصر: المؤسسة المصرية للطباعة والترمة والنشر، 


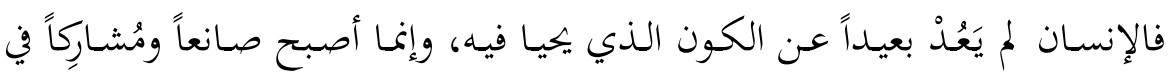

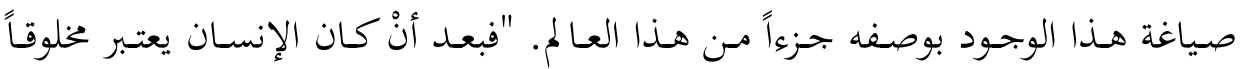

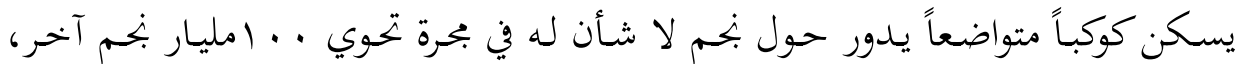

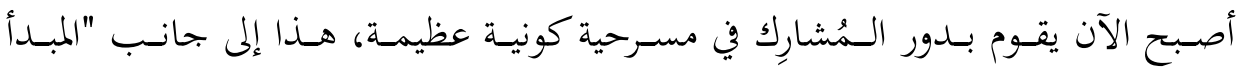

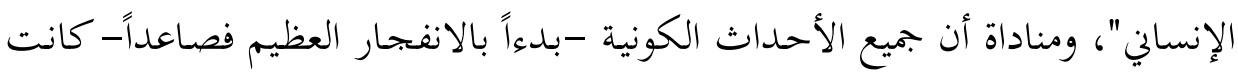

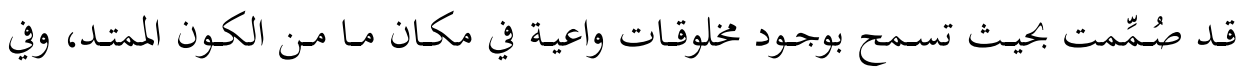

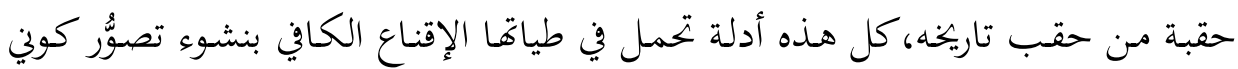

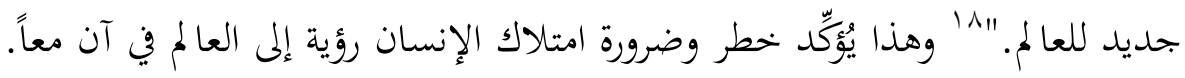

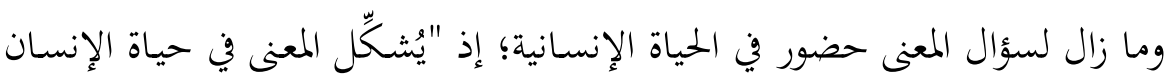

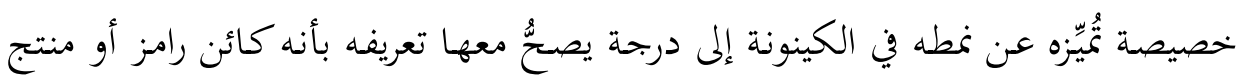

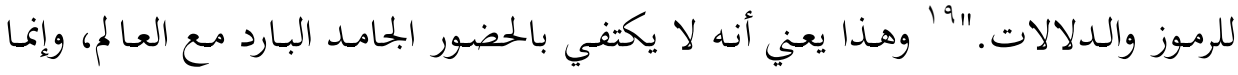

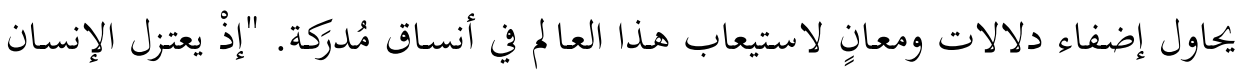

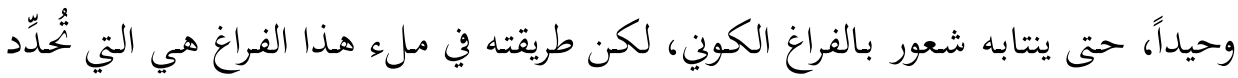

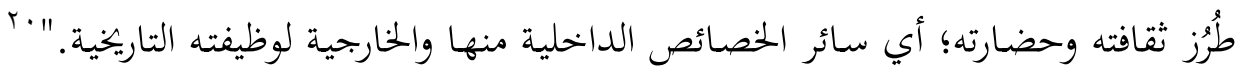
فحالة الفراغ الوجودي والكوني منعدمة لدى الإنسان.

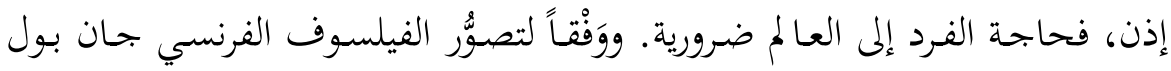

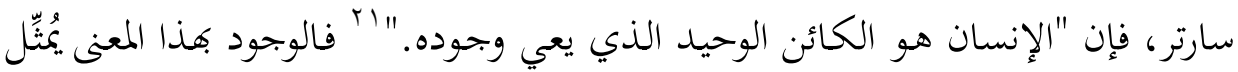

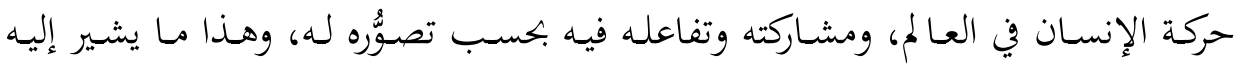

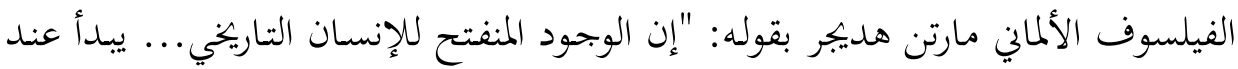

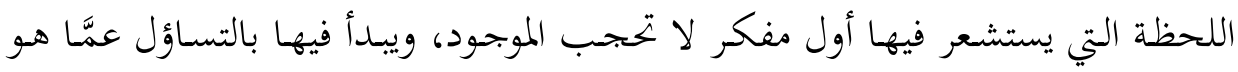
1' أغروس، روبرت، وستانسيو، جورج. العلم في منظوره الجليد، ترجمة: كمال خلايلي، الكويت: الجلس الألعلى للثقافة والآداب،

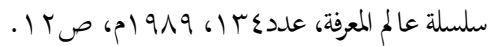
بوعزة، الطيب. "مفهوم الرؤية إلى العالم بوصفه أداة إجرائية لقراءة تاريخ الفكر الفلسفي"، مجلة تبين للدراسات

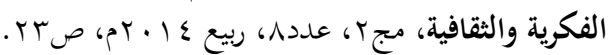

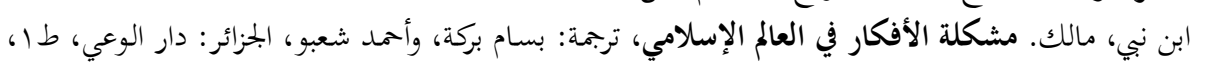
${ }^{21}$ J.P.S artre. l'Etre et le Néant, pris: Gallimard, 1951, P267.268. 


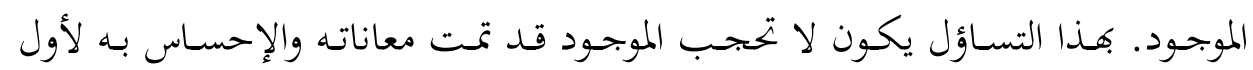

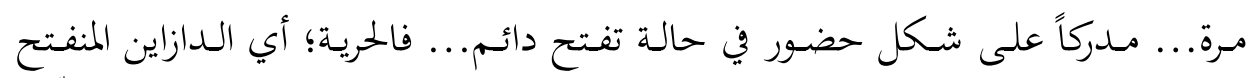

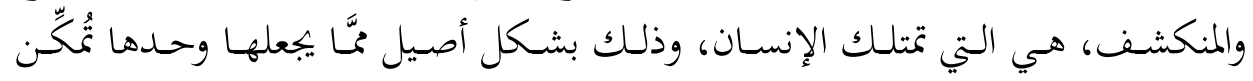

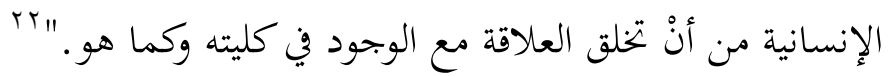

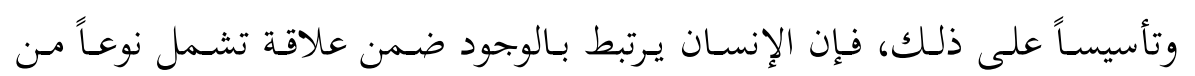

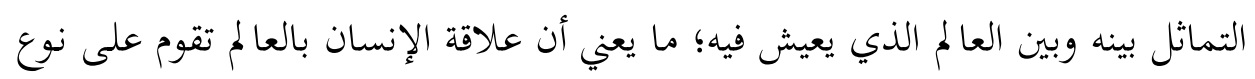

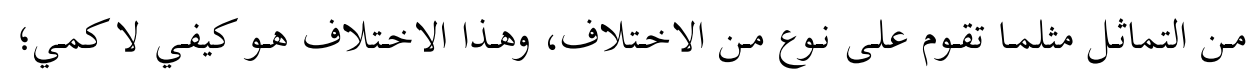

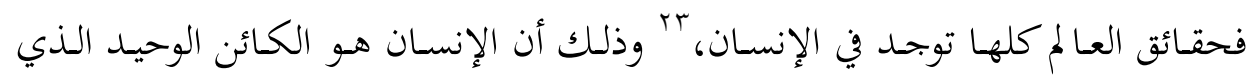

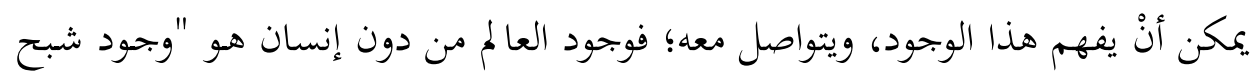

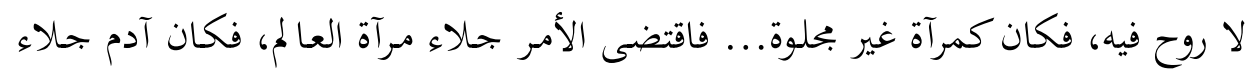

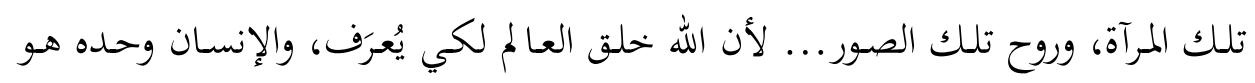

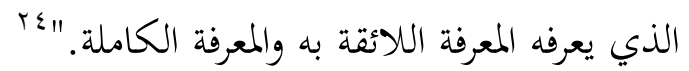

إن هذا المعنى الوجودي لرؤية العالم -في حضوره وملازمته للفكر الإنساني - يُؤِّدّد

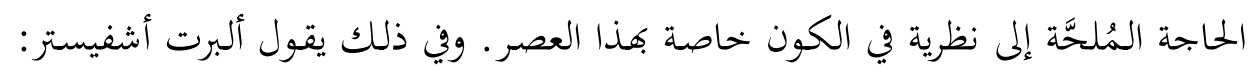

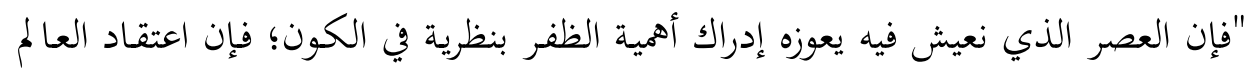

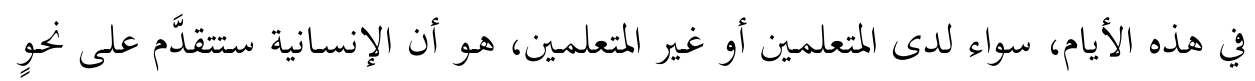

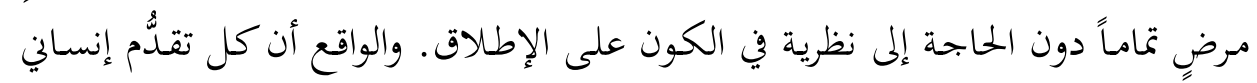

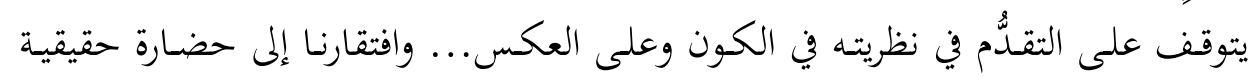

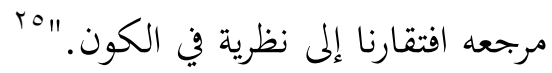

rr هيدجر، مارتن. التقنية، الحقيقة، الوجود، ترجمة: محمد سبيلا، وعبد المادي مفتاح، الدار البيضاء: المركز الثقافي

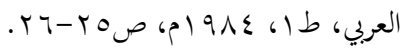

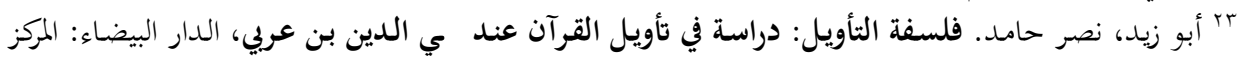

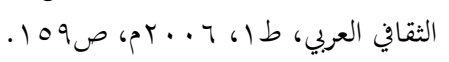

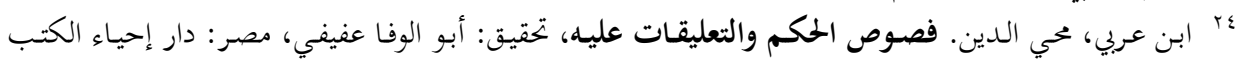

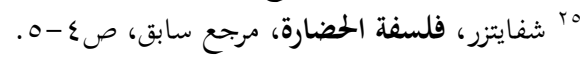


وعلى هذا، فإن الإنسان هو المُرشَّح لتقديم تصوُّر عن العالمه، ولا يمكن لأحد غيره

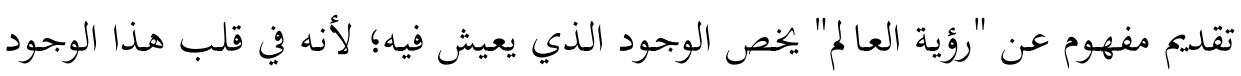

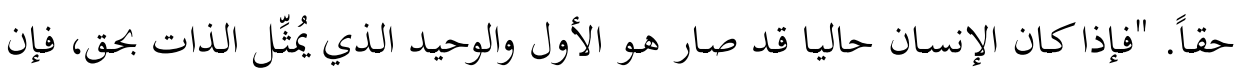

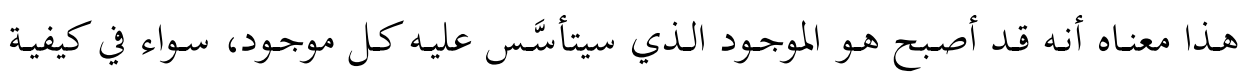

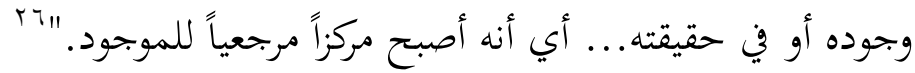

إذن، أصسبحت الـذات الإنسـانية تتمثَّل العـالم وتتصـوَّره وَفْـق رؤيسة معيَّنـة؛ فهـي

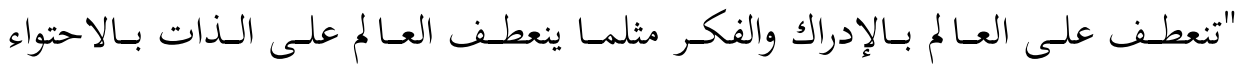

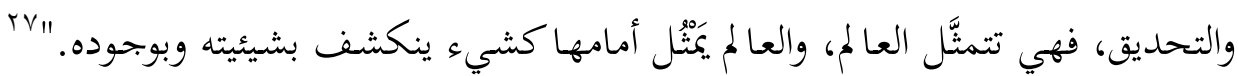
وهذا يعني أن فكرة الكلي وضرورة امتلاك تصوُّر عن العالمُ ظلَّت تطارد الإنسان، ويُّوّكّد

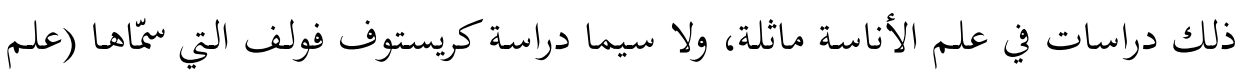

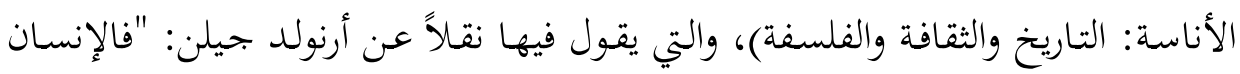

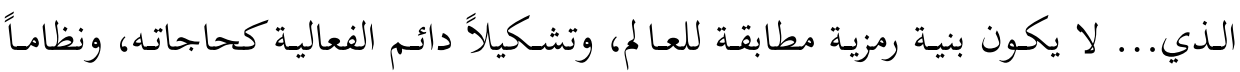

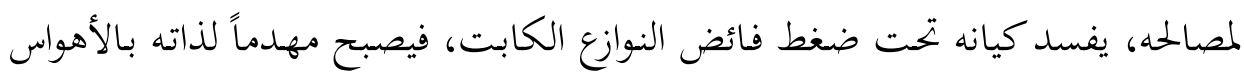

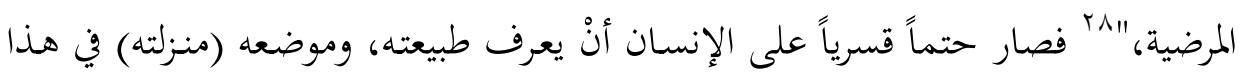

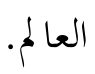

وما يزال صدى البحوث والأنثروبولوجيا والأركيولوجيا والدراسـات العلمية يتردَّد في

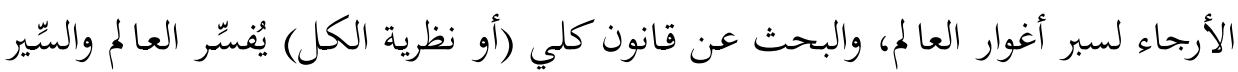

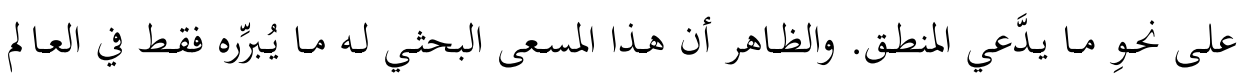

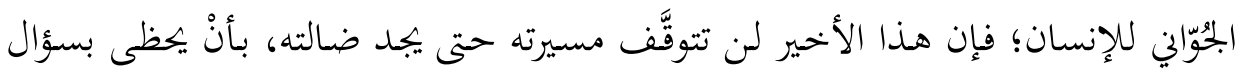

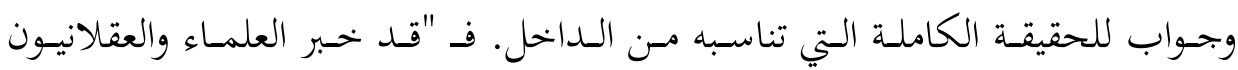

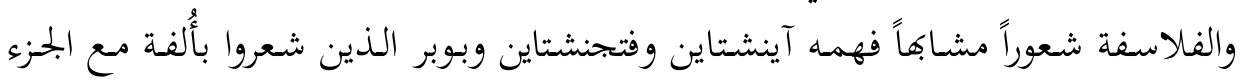

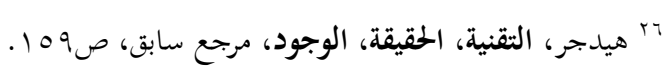

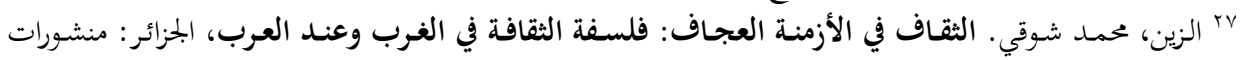

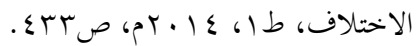

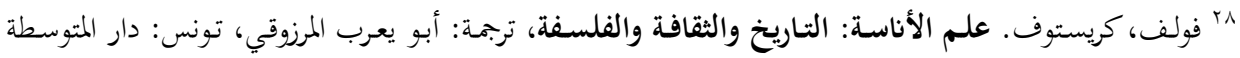

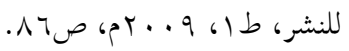




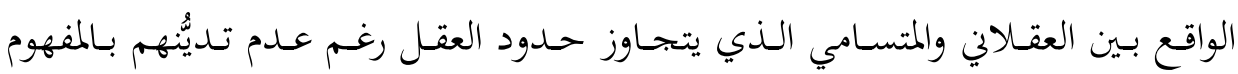

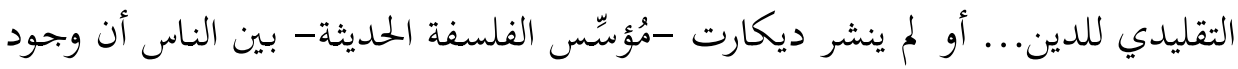

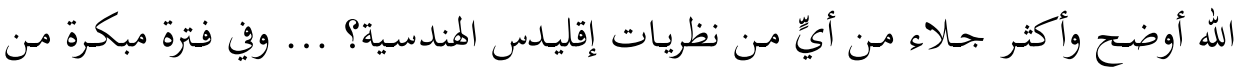

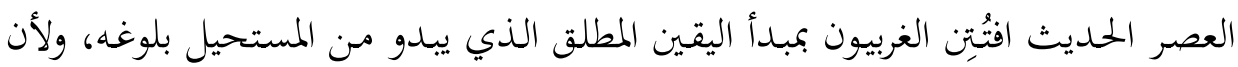

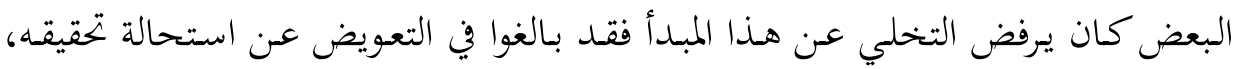

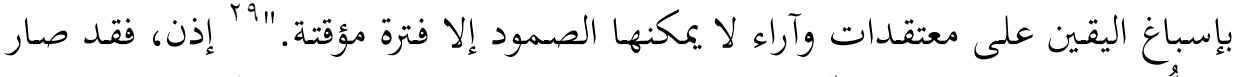

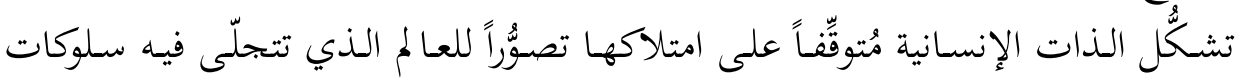

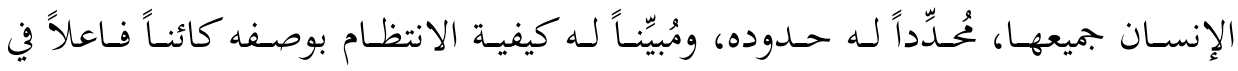

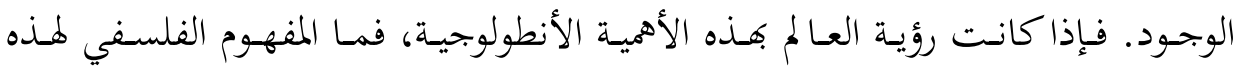

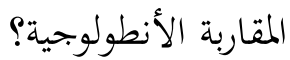

ثالثاً: الحدود الفلسفية لمقاربة مصطلح "رؤية العالم" 1 ـ علاقة المصطلح بالنسق الفلسفي:

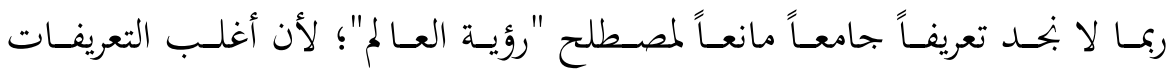

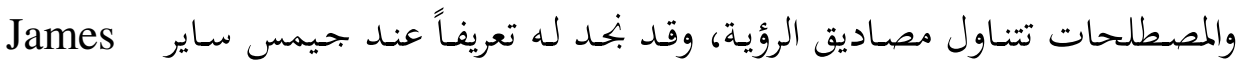

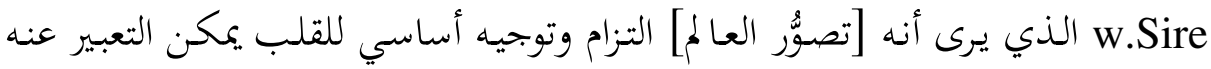

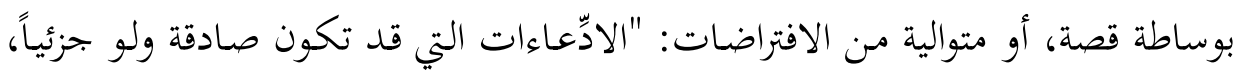

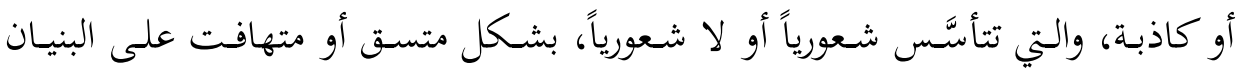

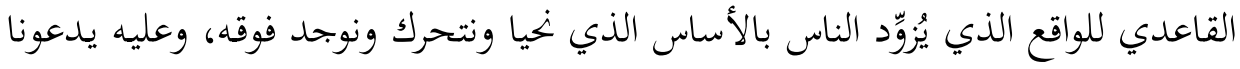

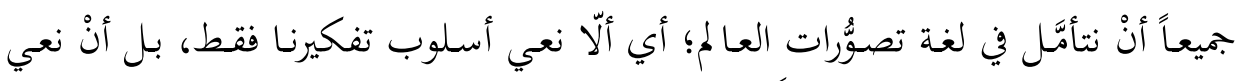

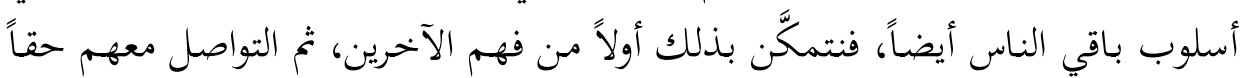

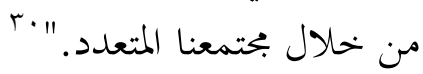

9' آرمسترونج، كارن. مسعى البشرية الأزلي، الله لماذا؟ ترجمة: فاطمة نصر، وهبة عممود عارف، القاهرة: الميئة

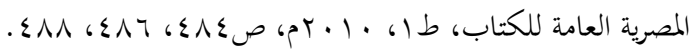

${ }^{30}$ James W. Sire. The Universe Next Door: A Bassic Worldview Catalog, 5 th edition, Intervarsity Press, 2009, p.15-16 


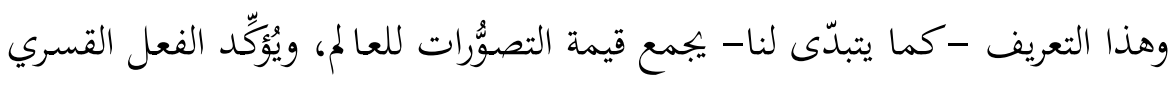

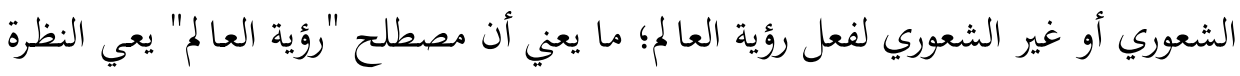

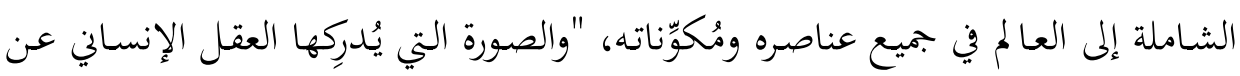

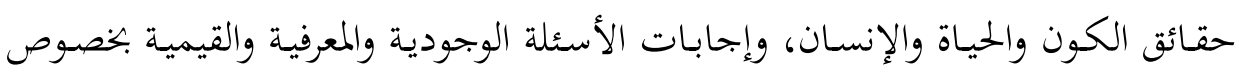

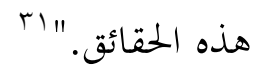

وتأسيساً على ذلك، يمكن اعتبار المنظومات الفلسفية -منـذ بـدايتها- رؤية إلى فئل

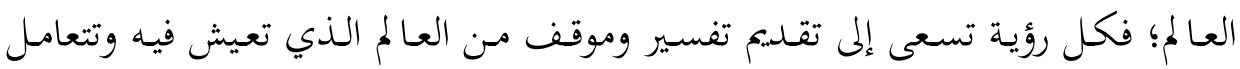

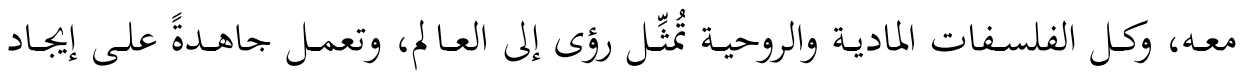

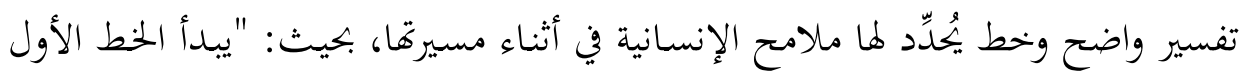

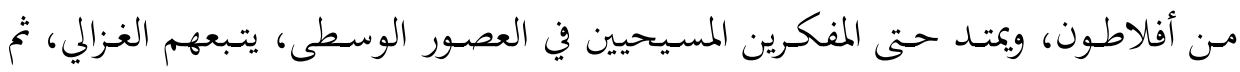

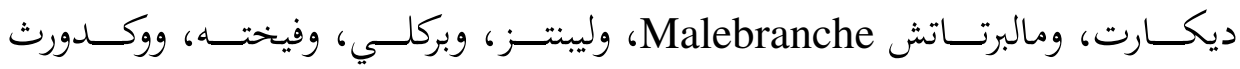
Cudworth

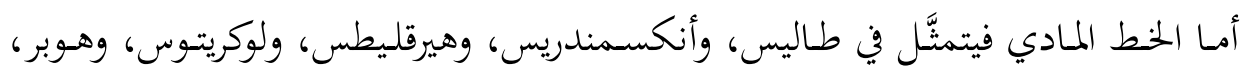

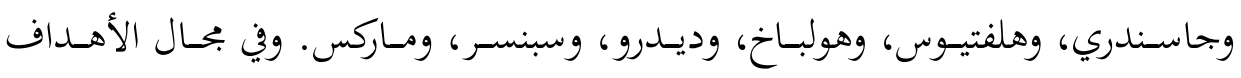

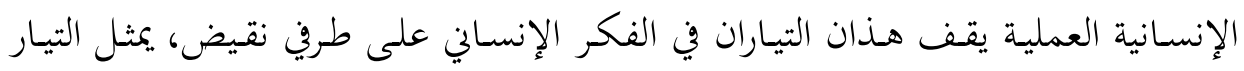

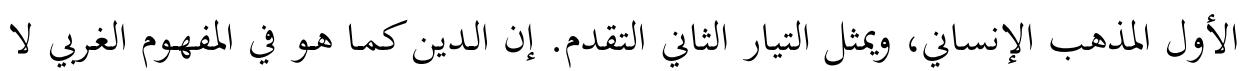

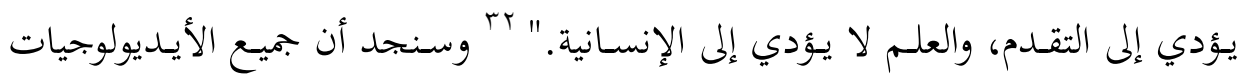

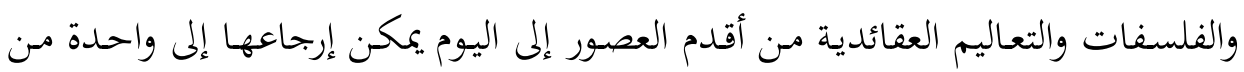
هذه النظرات الثلاث العالمية الأساسية: النظرة الدينية، والنظرة المادية، والنظرة الإسلامية. فالمثالية رؤية، والروحية رؤية، والوجوديو رؤية ونماذج تفسيرية. "والرؤية الكلية تمثل

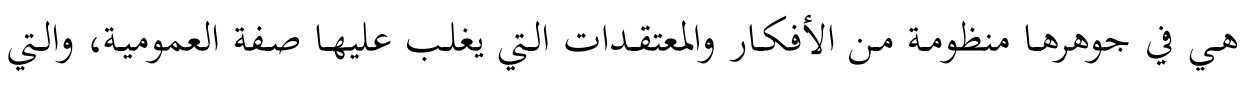

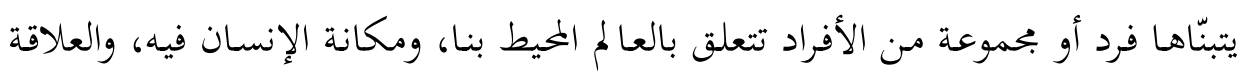
"rملكاوي، فتحي حسن. منهجية النكامل المعرفي: مقدمات في المنهجية الإسلامية، فرينيا: المعهد العلمي للفكر

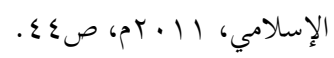
"rr بيجوفيتش، علي، عزت. الإسلام بين الشرق والغرب، ترجمة: يوسف عدس، مصر: دار النشر للجامعات، طج، 
بين الإنسان وعالمه، وعلاقة الإنسان بذاته، فضلاً عمَّا يتَّخذه الفرد وَفْقاً لتلك المنظومات من مواقف وآراء وأحكام حيال الكون والإنسانية والمستقبل."rr"

وعلى هـا، فإننا سنعرض -بشيء مـن الإسهاب- لنموذج يُمنّل الجحدل الواقع بين

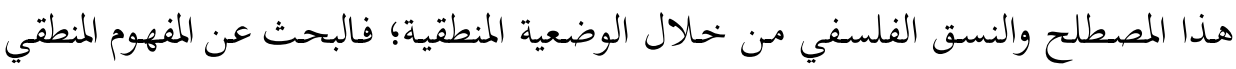

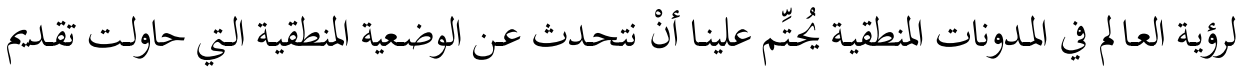

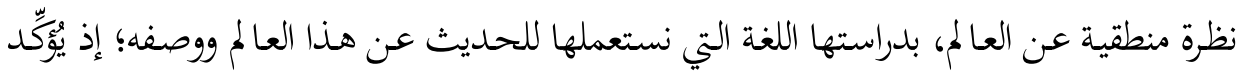
لودفيج فتجنشتاين Ludwig Wittgenstein في كتابه "الرسالة الفلسفية المنطقية" ما يأتي: " أ.

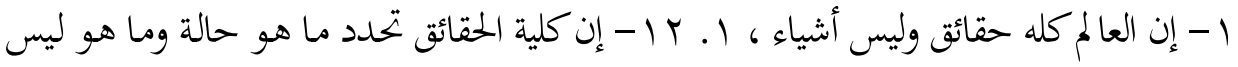

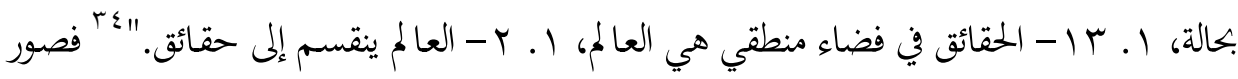

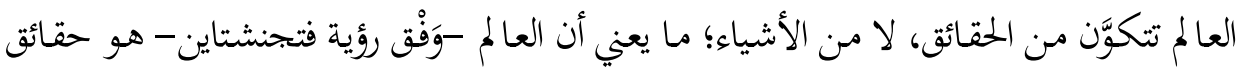

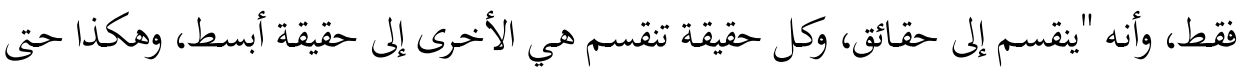

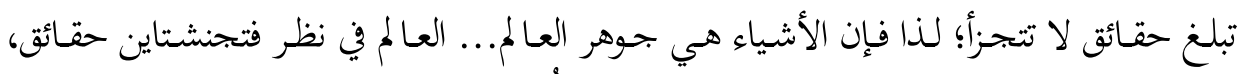

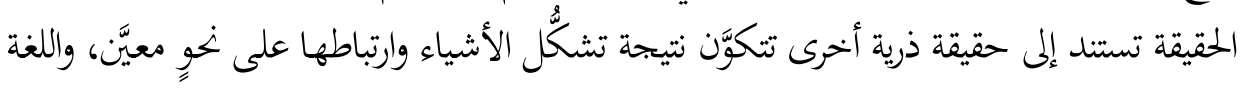

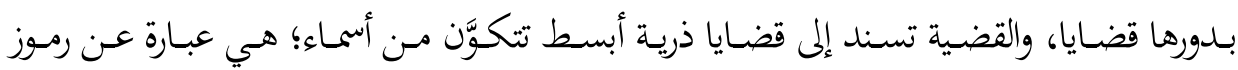

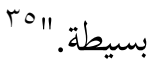

وبذلك يُوِّّد أصحاب الوضعية المنطقية أهمية اللغة التي نستخدمها في وصف هذا العالم؛ وذلك أن وظيفة اللغة هي الرسم والصورة؛ أي رسم العالم الخارجي وتصويره. "فالعالم يتكوَّن من

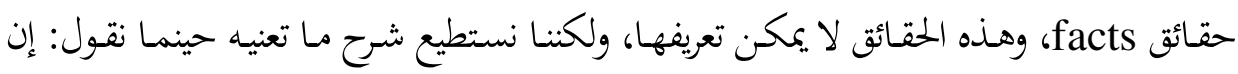

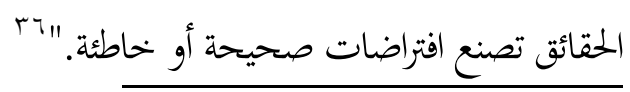

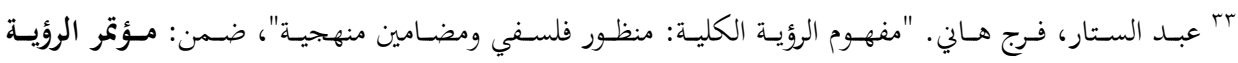

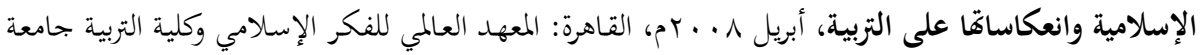

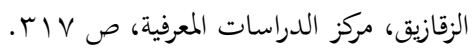

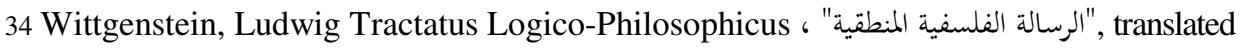
by: D. F. Pears and B. F Mc Guinness, Taylor \& Francis e- library, 2002, p. 5.

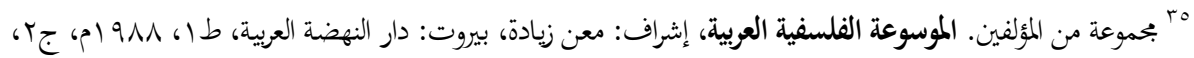
ص

36 Wittgenstein, Ludwig Tractatus Logico-Philosophicus, Introduction by Bertrand Russell, op cit. page xii-xiv. مقدمة كتاب الرسالة الفلسفية المنطقية بقلم برتراند رسل 
وهذا ما أحسن توظيفه رودولف كارناب Rudolf Ca rnap ؛ إذ إنه استفاد من كتاب فتجنشتاين "الرسالة الفلسفية المنطقية"، وذلك بتحويله "إلى برنامج فلسفي عملي، مُهتدِياً بما قاله

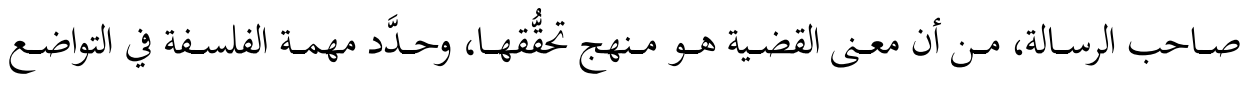

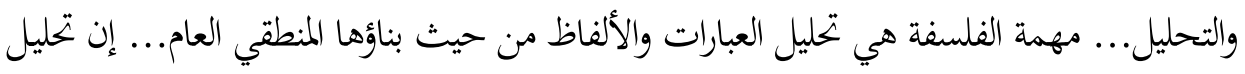

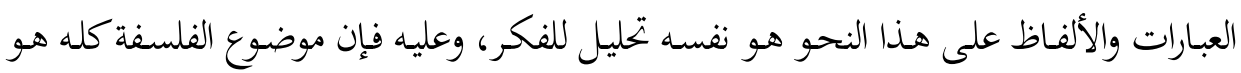

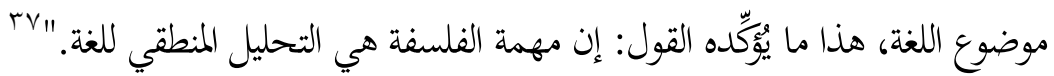
وهذا ما حاول كارناب فعله، وسعى إلى تحقيقه في كتابه "البناء المنطقي للعالم والمسائل الزائفة

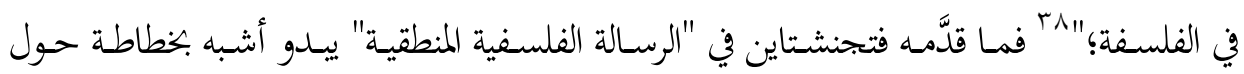

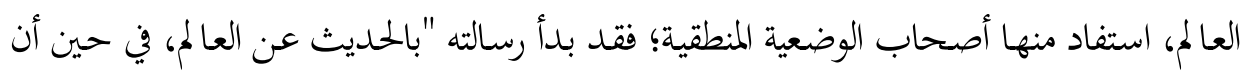
الغرض الأساسي من فلسفته في هذه الرسالة هو تحليل اللغة، وبيان كيف يكون سوء فهمنا لمنطقها هو السبب في كثير من المشكلات الفلسفية، وكان الأَلى به أنْ يبدأ بحثه باللغة وتحليلها، إلّا أنه فئه

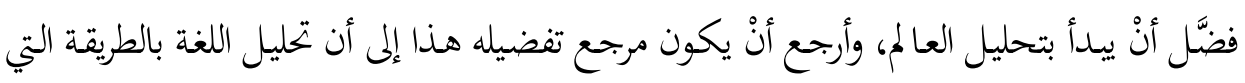

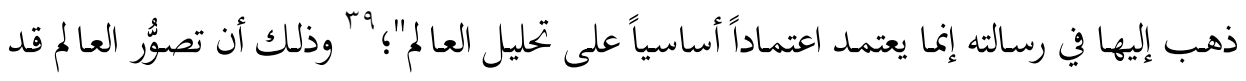

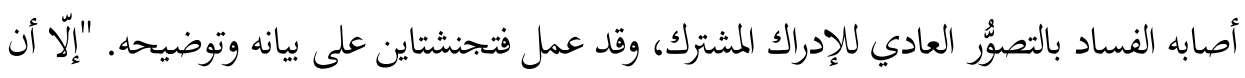

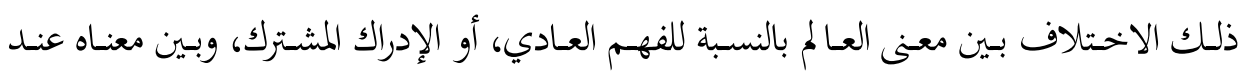

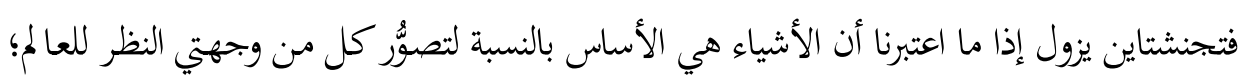
لأن الوقائع عند فتجنشتاين ولو أهما هي الوحدات الأولى التي ينتمي إليها تحليلنا للعالم، إلا أها في

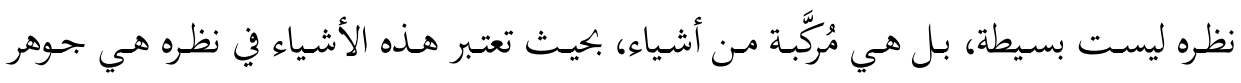

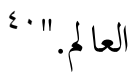

غير أن هذه المسألة (أي تحليل العالم عن طريق اللغة) تستمر مع الوضعية المنطقية في استبعاد

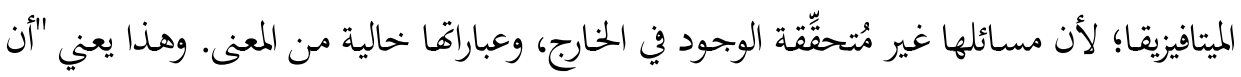

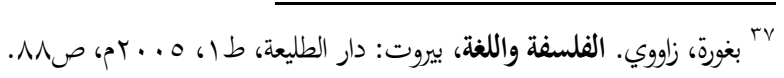

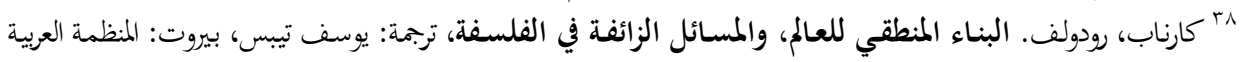

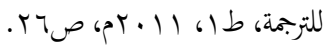

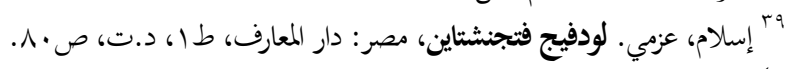

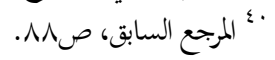




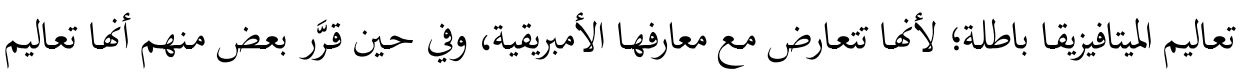
غير يقينية على اعتبار أن مشاكلها تتجاوز حدود المعرفة البشرية... عندما أقول: إن قضايا الميتافيزيقا

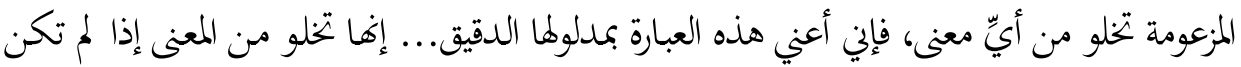

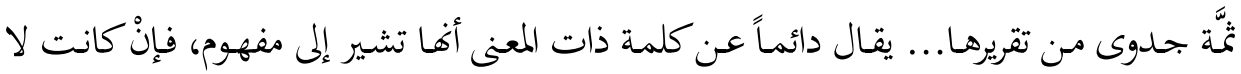

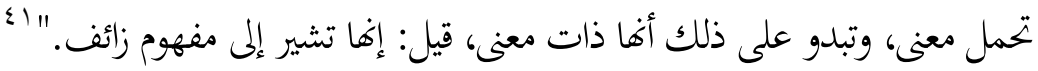

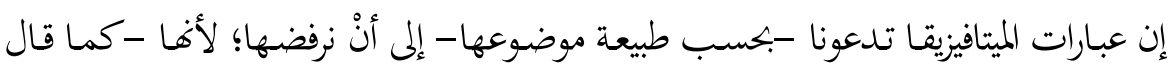

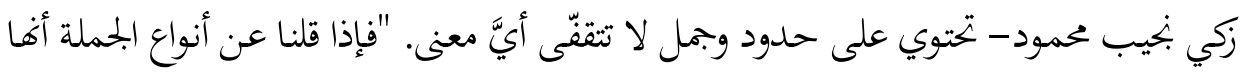

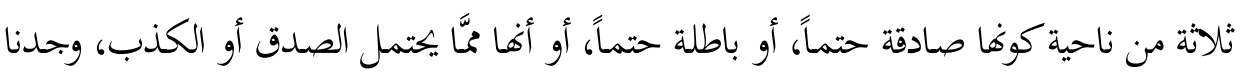

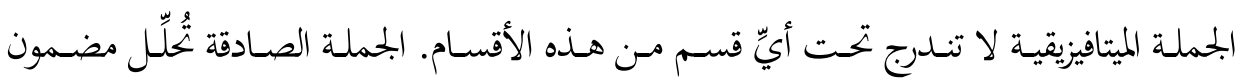

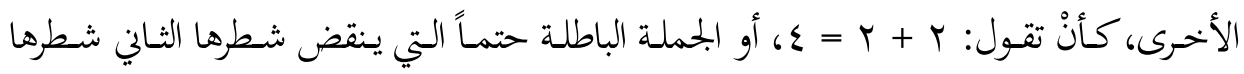

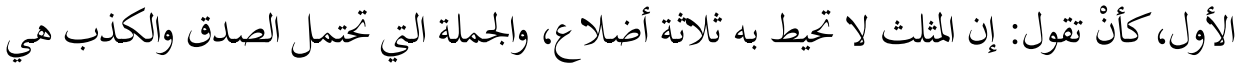

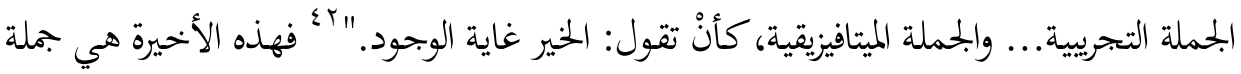

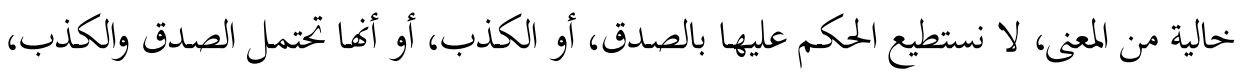

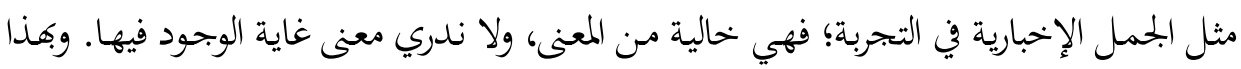

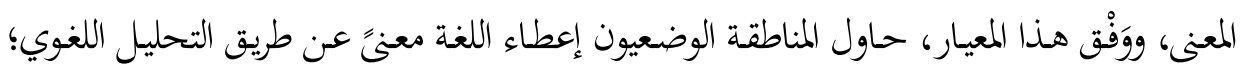

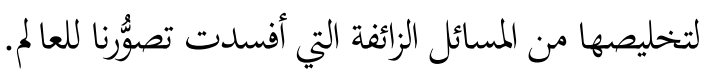

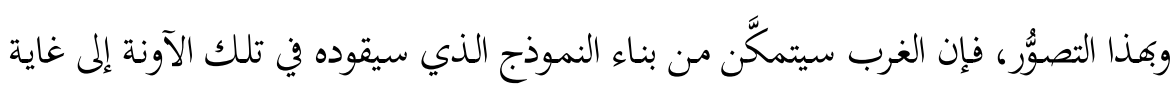

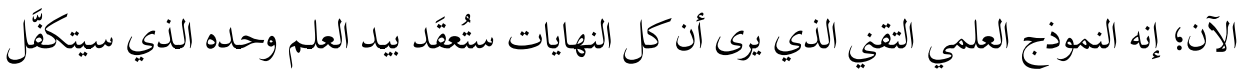

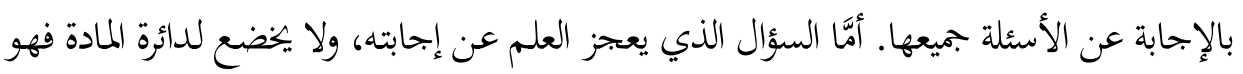

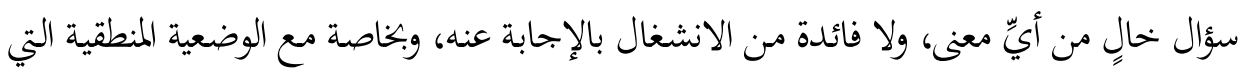

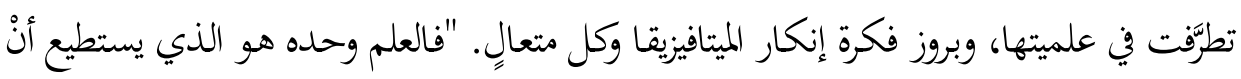

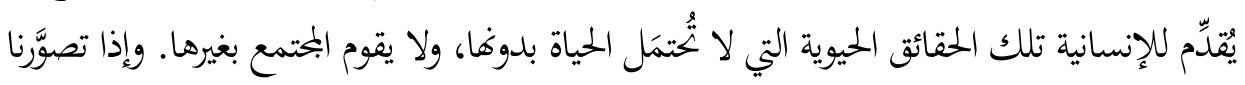

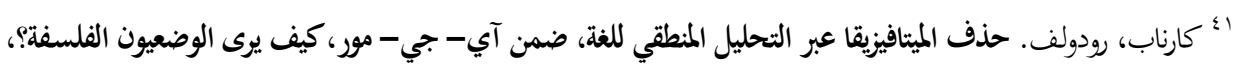

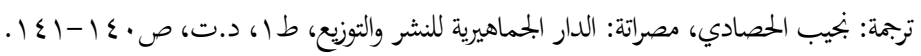

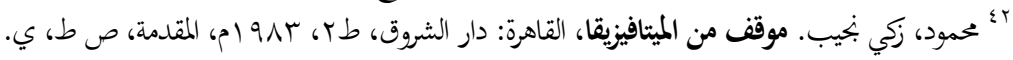




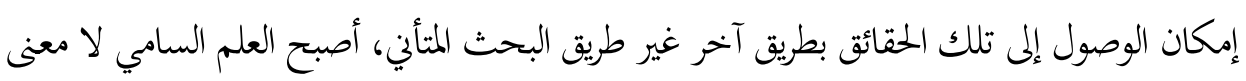

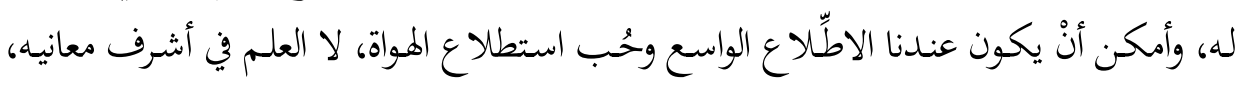

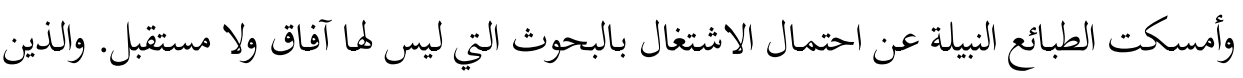

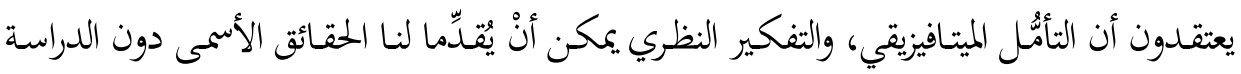

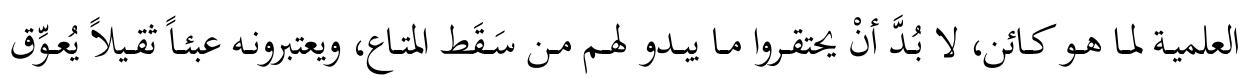

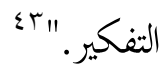

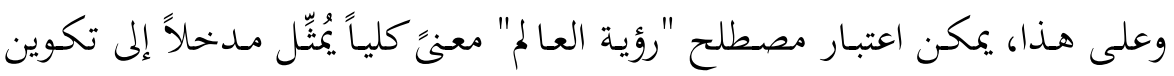

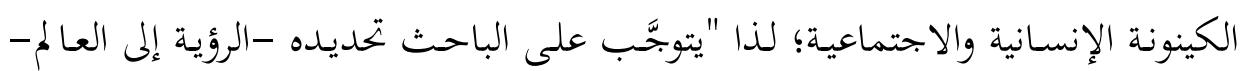

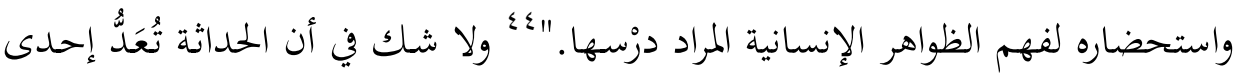

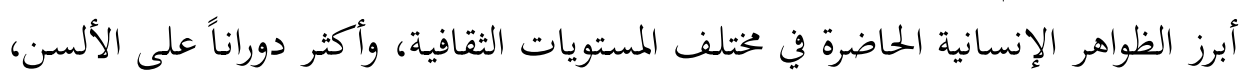
بوصفها حدثاً عالمياً ثقافياً تاريخياً.

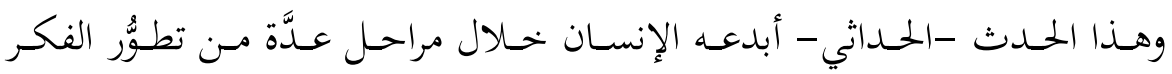

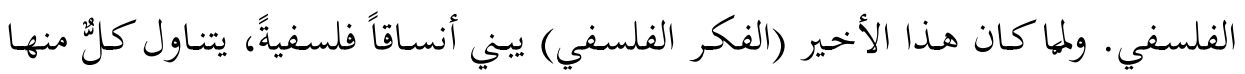

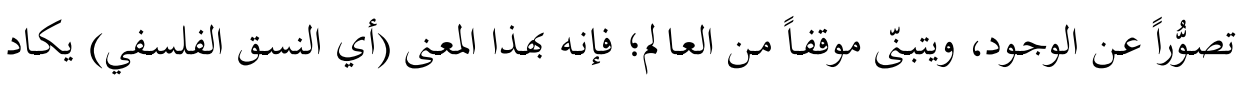

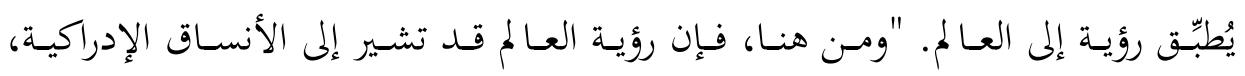

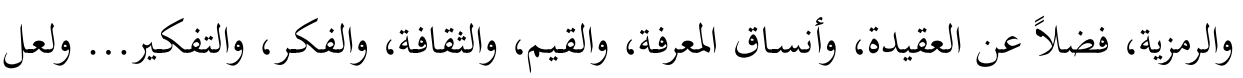

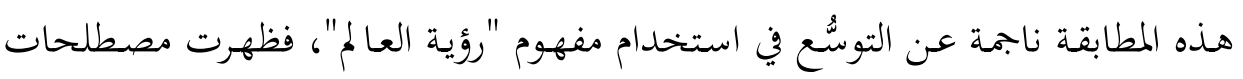

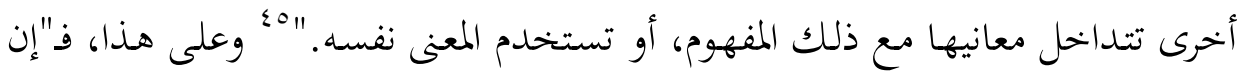

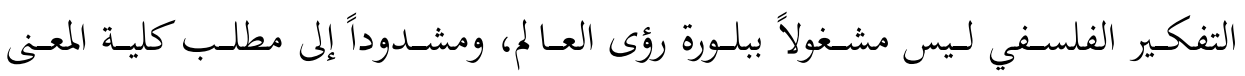

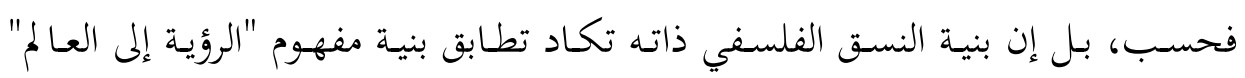

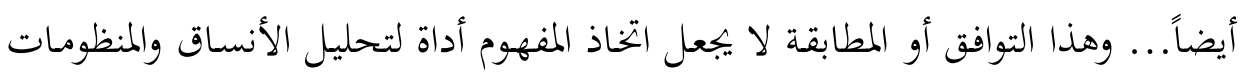

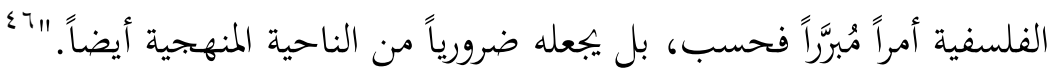

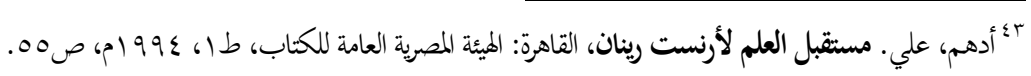

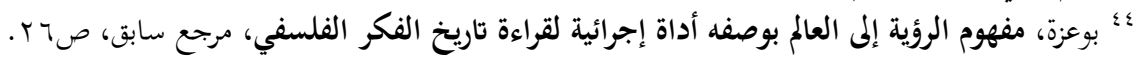

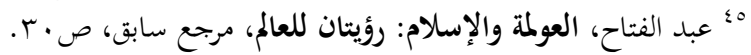

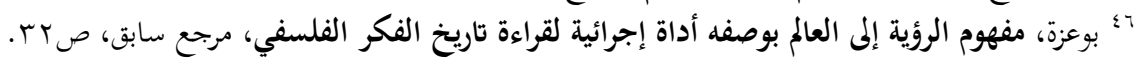




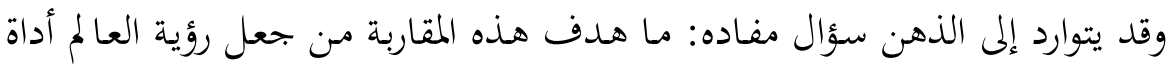

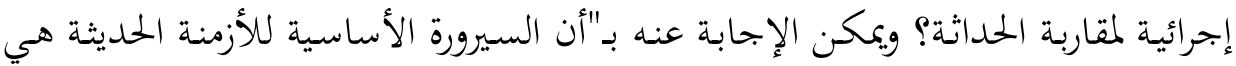

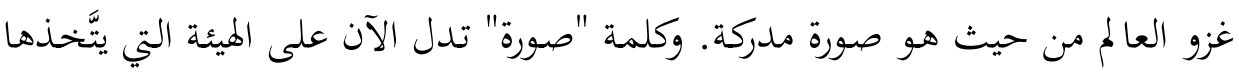

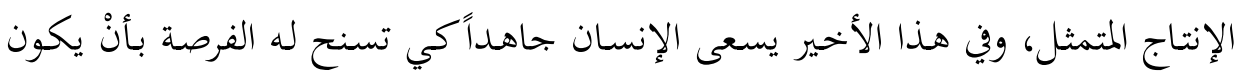

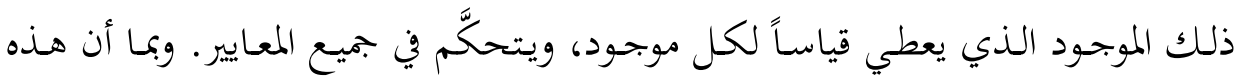

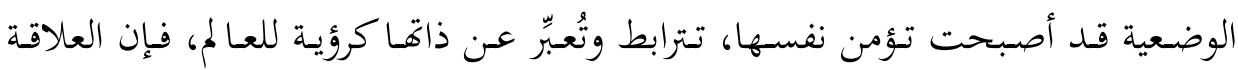

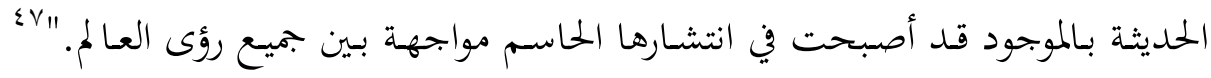

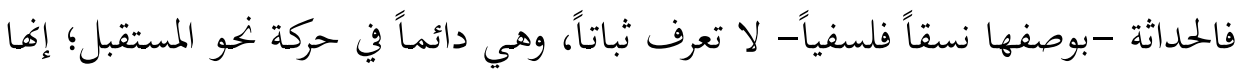

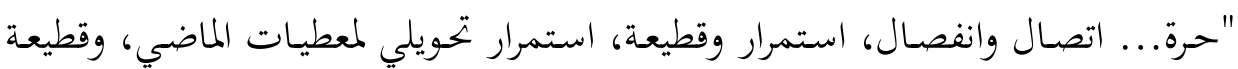

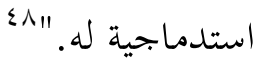

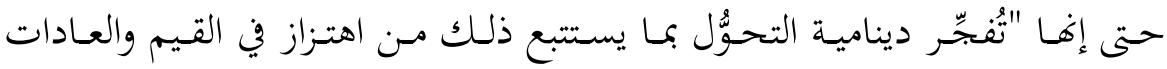

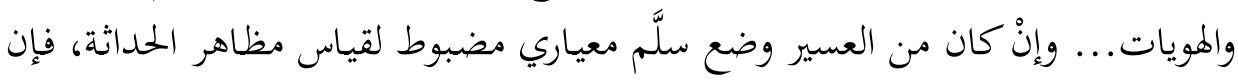

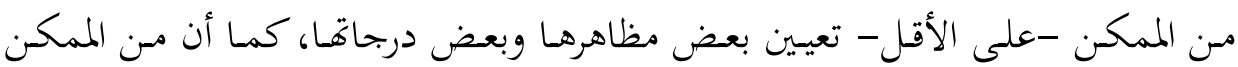

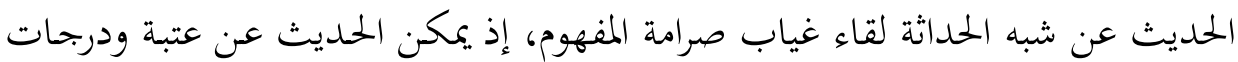

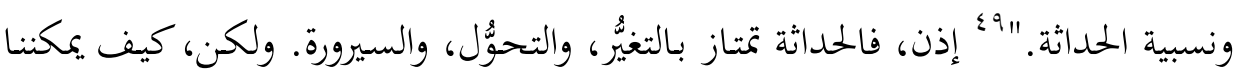

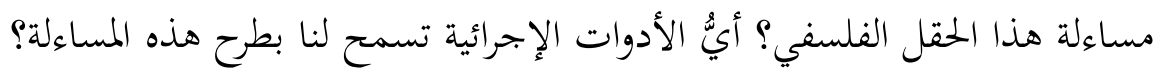
لقد أشرنا سابقاً إلى أن بنية النسق الفلسفي تطابق بنية مفهوم "رؤية العالم"، وأن المان

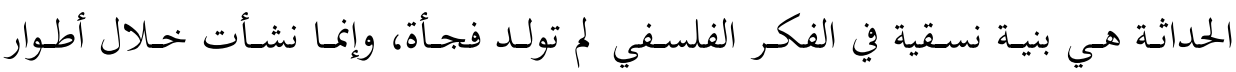

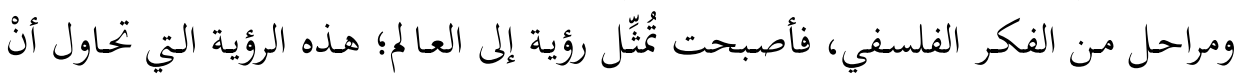

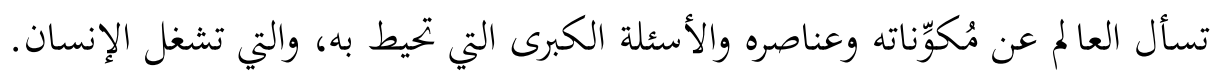

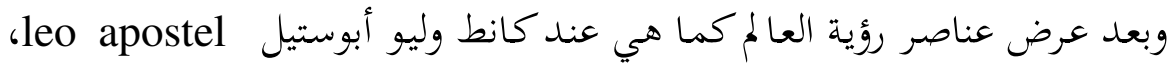

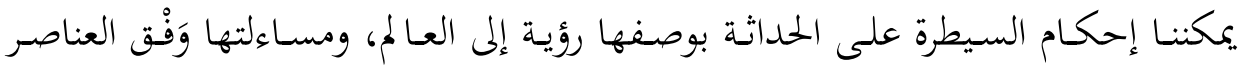

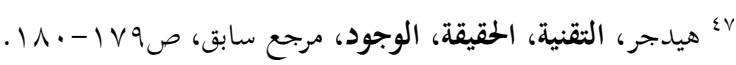

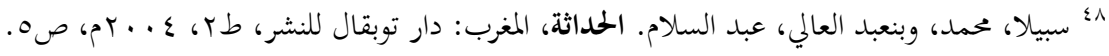

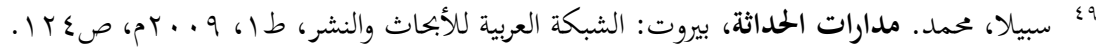




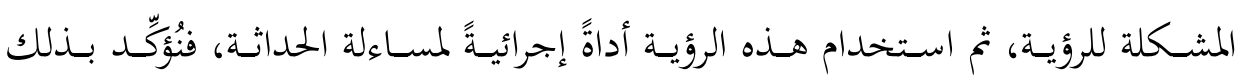

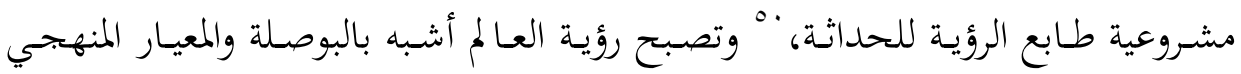

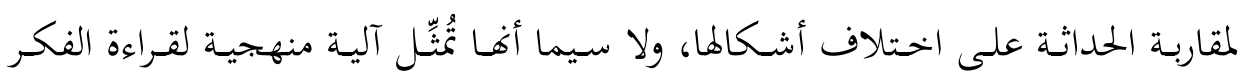
الفلسفي -وبخاصة الحداثي منه- الذي كان شعاره التحوُّل والتغيُّر.

\section{Y. أسئلة المصطلح الكبرى في الفلسفة:}

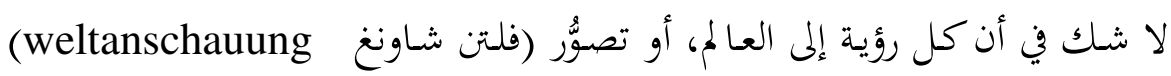

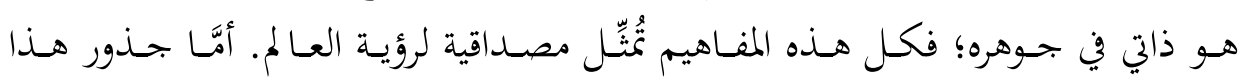

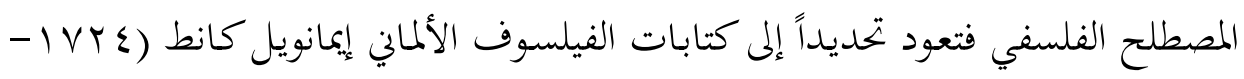

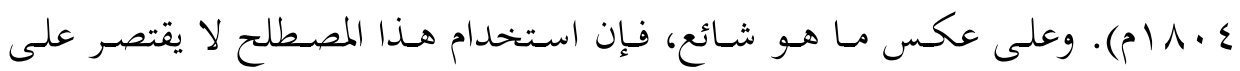

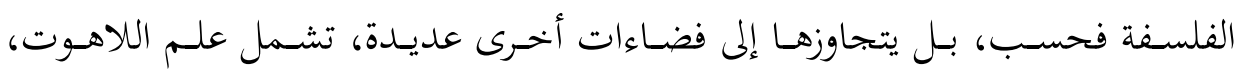

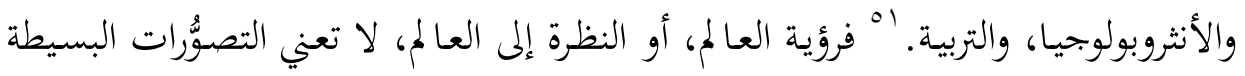

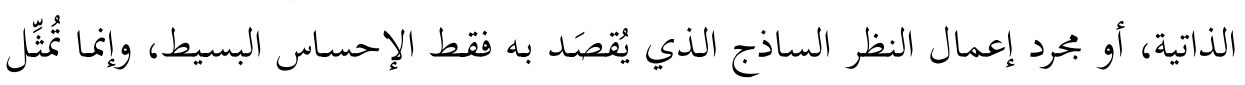

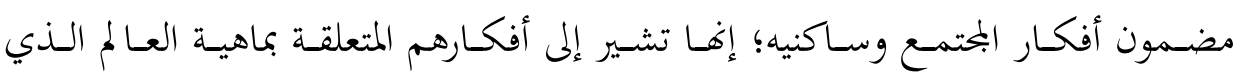

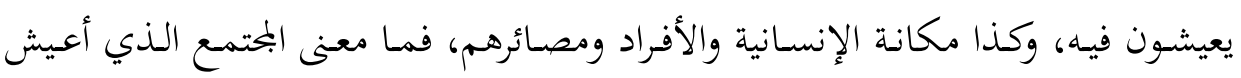

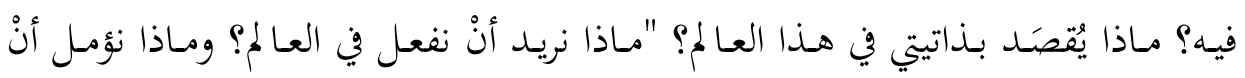

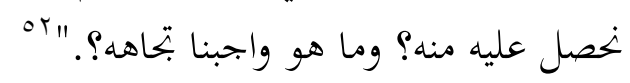

وهـذه الأسئلة التي تُمثِّل أسئلة البدايات والنهايـات، أو أسئلة المبـدأ والمسـير والمصسير

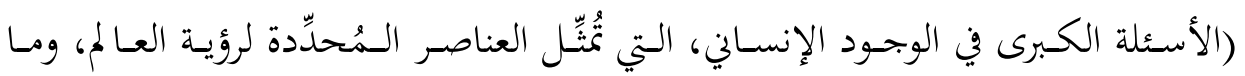

• ئ يرى بعض الدارسين أن الرؤية الحداثية هي التصور العلمي للعالم المحصور في جانبه المادي والحتماني، وأن "العالم.

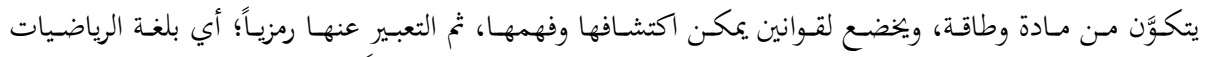

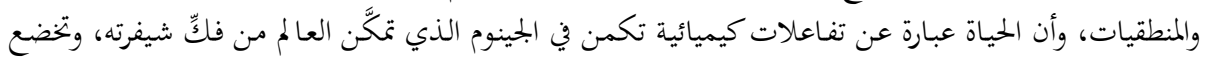

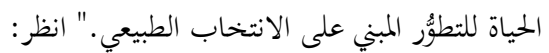

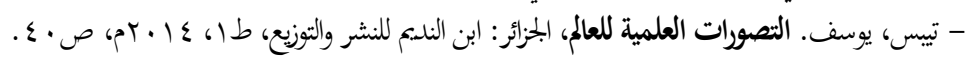

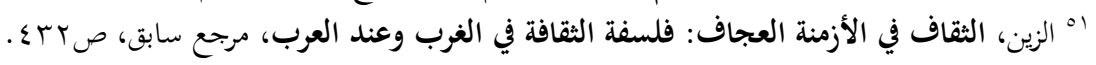

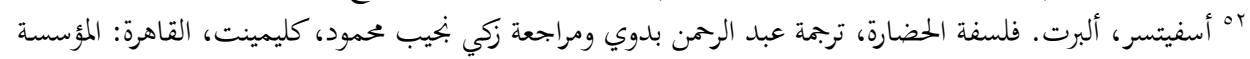

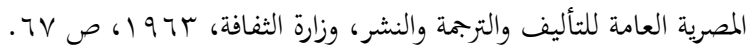


يقارب هذه الأسئلة في محاولة صياغة تصوُر كلي للعالم)؛ تمتد جذورها لتصل الفيلسوف الألماني كانط، الذي أفرد لكل سؤال منها كتاباً فلسفياً على النحو الآتي : أ. "ماذا يمكنني أن أعرف؟"هاه (سؤال المعرفة؛ السؤال الرئيس الذي تدور حوله فكرة الكتاب). وقد أفرد له كتاب "نقد العقل المخض". ب. "ماذا يجدر بي أنْ أفعل؟"؛ُ (سؤال الأخحلاق). وقد أفرد له كتاب "نقد العقل العملي" ت. "ماذا يحق لي أنْ آمل؟"0 (سؤال الدين). وقد أفرد له كتاب "الدين في حدود

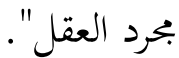
ث. مـا هو الإنسان؟ (سؤال الفلسفة والأنثروبولوجيا)، غير أنه أكَّدـ في رسالة... "أن المخطط الذي وصفته منذ وقت طويل للعمل الملقى على عاتقي في ميدان الفلسفة

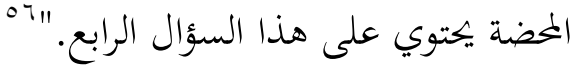
ويمكن لنا أنْ نتلمَّس الجحواب عن السؤال الرابع في رسالة كانط (ما هو التنوير؟)؛؛ إذ إنه يشير في مشروعه إلى الإنسان الذي يريد. يقول في ذلك: "ما هو عصر الأنوار؟ هو خروج الإنسان مـن حالة القصور الذي يبقى هو المسؤول عن وجـوده فيها. والقصسور

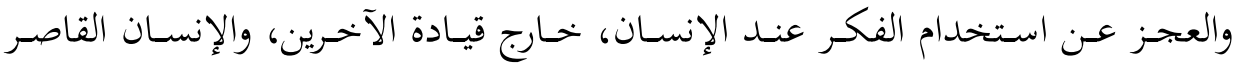

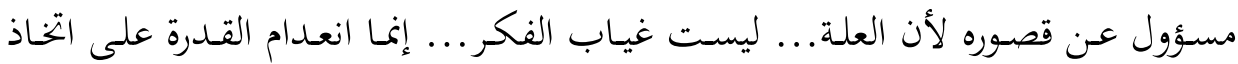

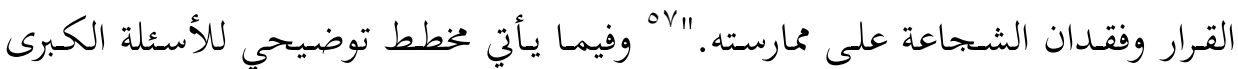

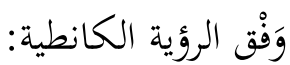

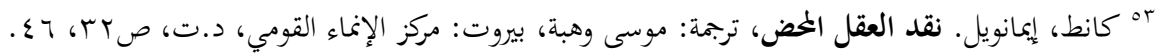

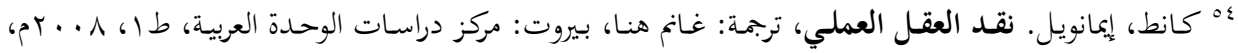
• كانط، إمانويل. الدين في حدود مجرد العقل، ترجمة: فتحي مسكيني، بيروت: جداول للنشر والتوزيع، طا،

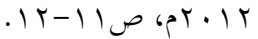

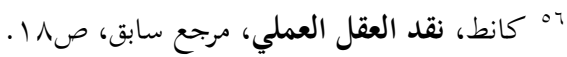

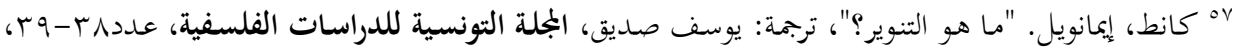




\begin{tabular}{|c|c|c|}
\hline الكتاب & الميدان & السؤال \\
\hline نقد العقل المحض & الإبستمولوجيا (نظرية المعرفة) & ماذا يمكنني أنْ أعرف؟ \\
\hline نقد العقل العملي & الأكسيولوجيا (القيم، & ماذا يجدر بي أنْ أفعل؟ \\
\hline الدين في بحرد حدود العقل & 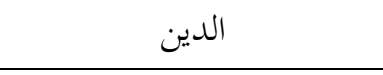 & ماذا يحق لي أنْ آمل؟ \\
\hline 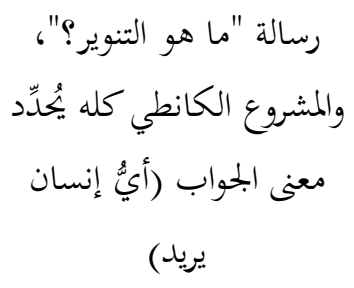 & سؤال الفلسفة والأنثروبولوجيا & ما هو الإنسان؟ \\
\hline
\end{tabular}

لقد حصر كانط الأسئلة الكبرى (لرؤية العالم) في أربعة أسئلة، ولكن هذه الأسئلة

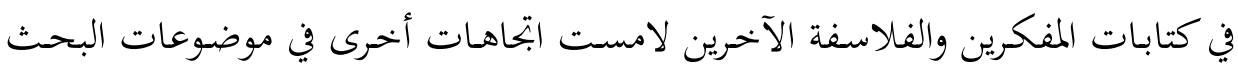
الفكري والفلسفي؛ إذ كانت "أهم وأدق محاولة لعرض كيفية بناء التصوير العلمي للعلم

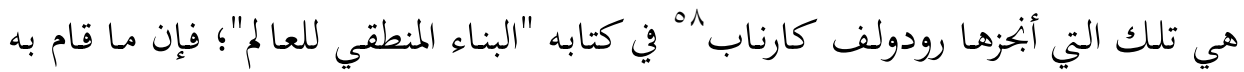
تلميذه ليو أبوستيل Leo Apostel من عرض اليُكوِّونات الأساسية والأسئلة الجوهرية

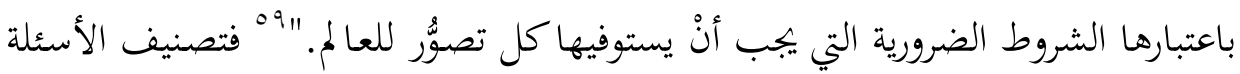

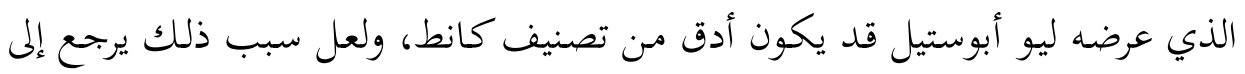

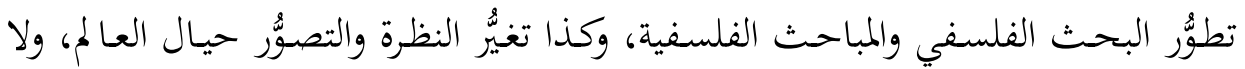

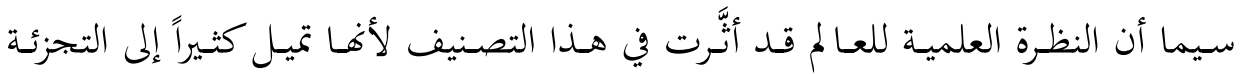

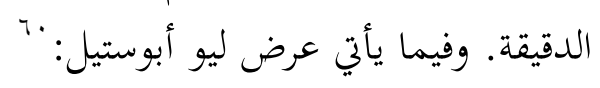

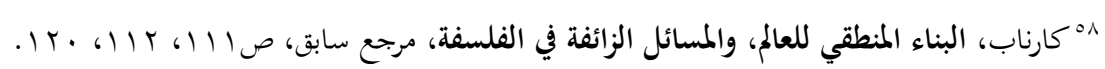

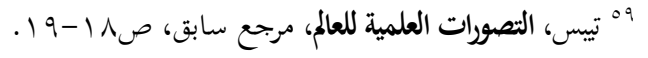

${ }^{60}$ Aerts, D., Apostel L., De Moor B., Hellemans S., Maex E., Van Belle H., Van Der Veken J., Worldviews: From Fragmentation to Integration, VUB Press, Brussels, 1994.

عنوان الكتاب: نظرات إلى العالم من التجزئة إلى التكامل، وللكتاب نسخة إلكترونية على الرابط: -http://pespmc1.vub.ac.be/CLEA/Reports/WorldviewsBook.html 


\begin{tabular}{|c|c|c|c|c|}
\hline التصوُر الديني & التصوُّر العلمي & الججال الفلسفي & المقولة & السؤال \\
\hline المادة، والفكر، & 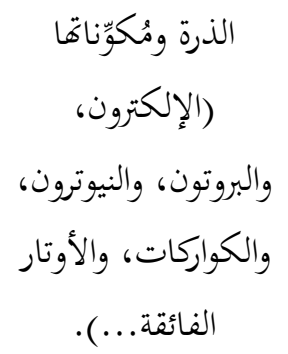 & الأنطولوجيا/ الثيولوجيا & المادة فقط. & ما ما الذي \\
\hline لحلق اللحق من عدم. & عن الانفجار الأكبر أوجد الأنواع المختحلفة & التفسير & أصل العالم أو & ما مصدر العالم الأنواع؟ ما \\
\hline 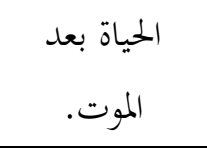 & يتوسَّع الكون وينتشر & التنبؤ & مصير العالم & إلى أين نسير؟ \\
\hline 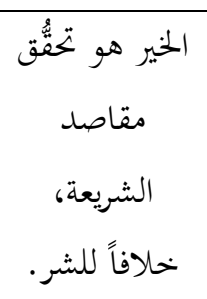 & والموضةعية، والعقلانية، والشجاعة. & نظرية القيم & القيم الواجبة & ما ما الخير؟ \\
\hline بالأوامر & البحثث في الظواهر العلمي: & نظرية الأفعال & السلوك & ما علينا الذيلوك اتِّاعه؟ \\
\hline 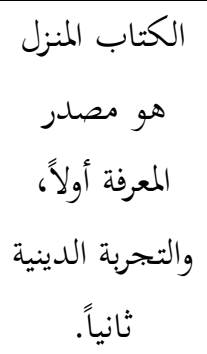 & للتحقق أو الإبطال. & نظرية المعرفة & معايير الحقيقة & ما الصواب؟ \\
\hline
\end{tabular}




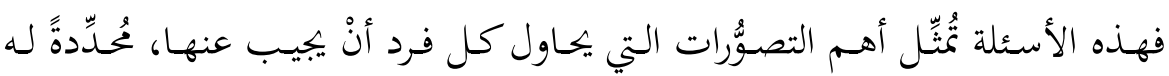
طرائق العيش. "وعلى هذا النحو فبإن كل الأفكار، سواء أكانت أفكار الأفراد أو أفكار

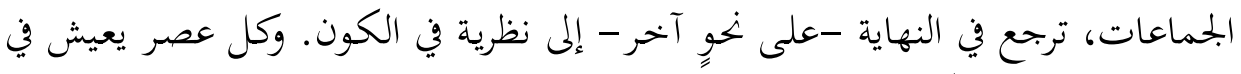

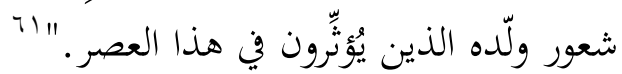

ولأن طبيعة البشر كذلك؛ إذ: "تميل أفعال الناس وأفكارهم إلى أنْ يهكمها -أو يُؤثِّ

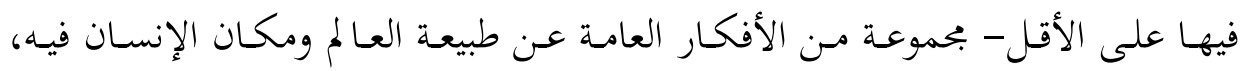

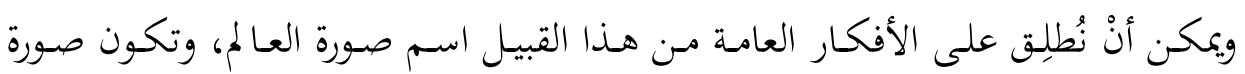

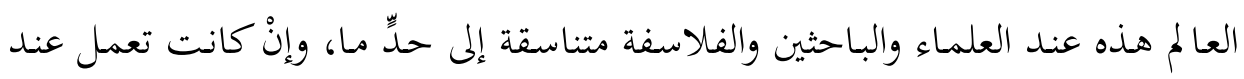

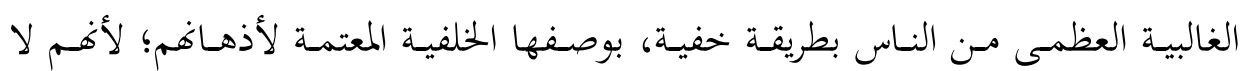

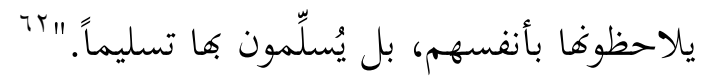

فإذا كانت الذات الإنسانية تميل إلى العيش في أُفق تُحاكم فيه الأفعال والتصرفات

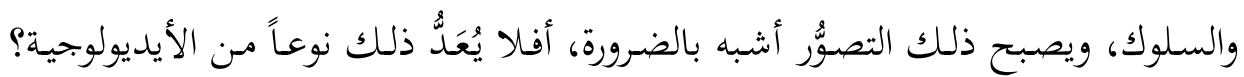

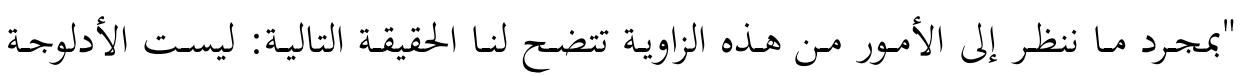

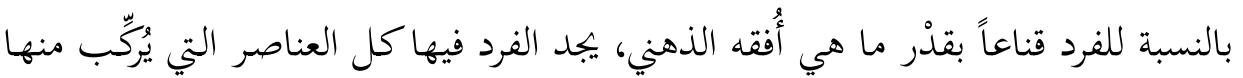

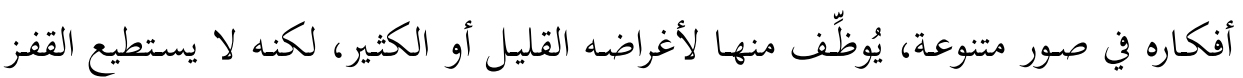
فوق حدودها، هي مرجعه الذهني والمنظار الذي يرى به ذاته وبحتمعه والكون كله." لقد أخذذت مسألة "رؤية العالم" تتبوَّأ مكانة مهمة بمـا تحوزه من عناصر للتطوُّرات

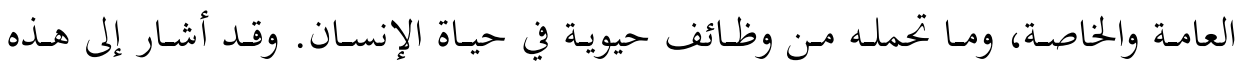

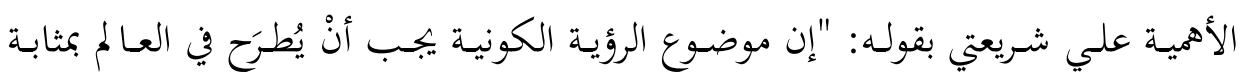

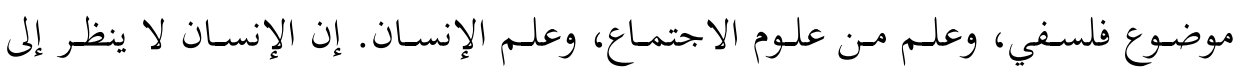

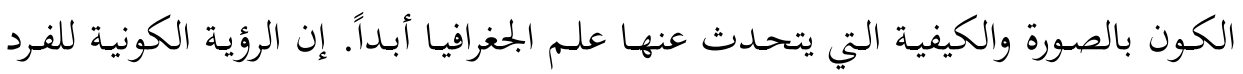

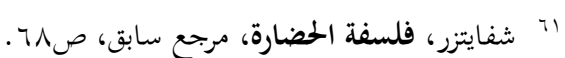

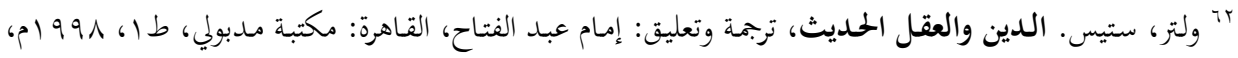




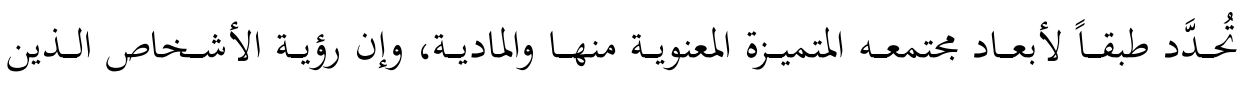

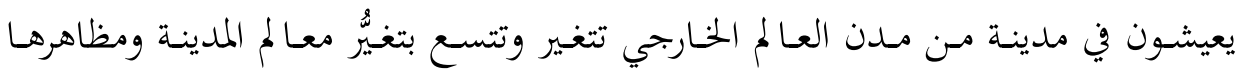

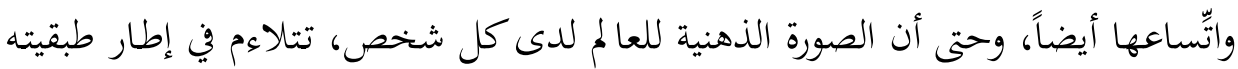

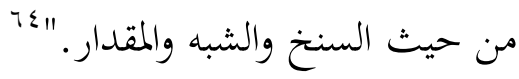

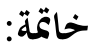

انتهى البحـثث إلى أن الحداثـة هي رؤيـة كليـة إلى العـالم، تحـاول السـيطرة عليـه،

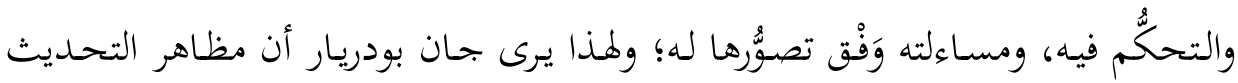

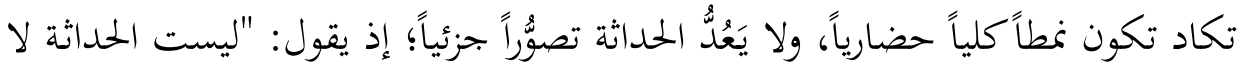

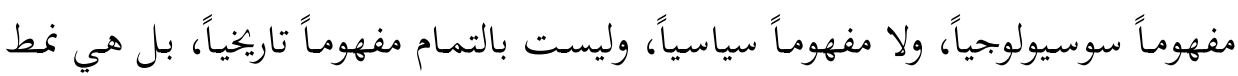

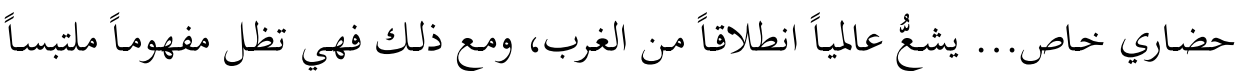

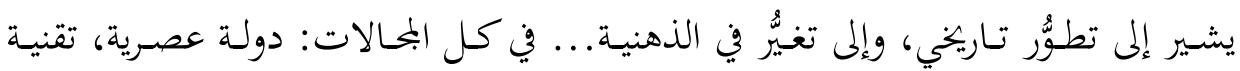

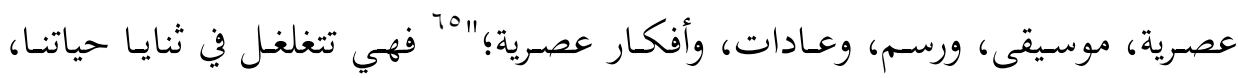

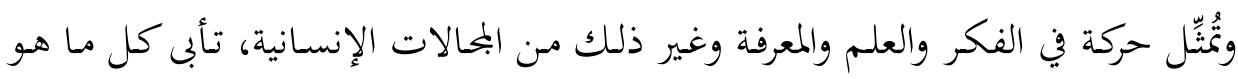

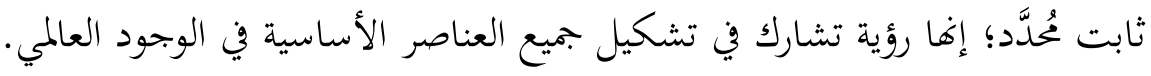

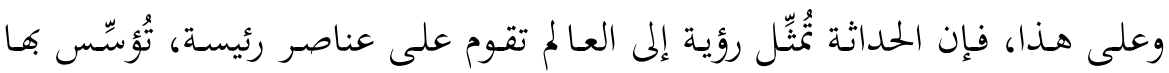

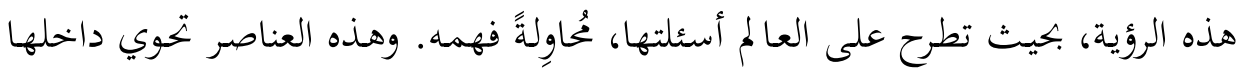

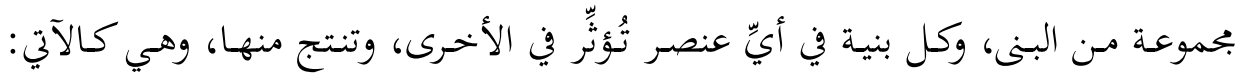

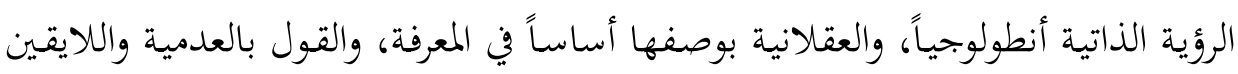

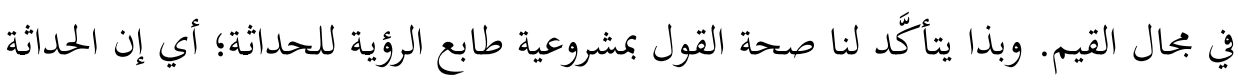
گ` شريعتي، علي. الإنسان والإسلام، ترجمة: عباس ترجمان، مراجعة: حسين علي شعيب، العراق: دار الأمير للثقافة

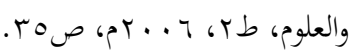

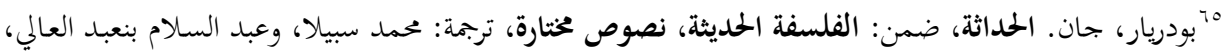

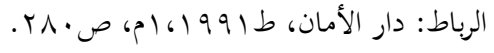




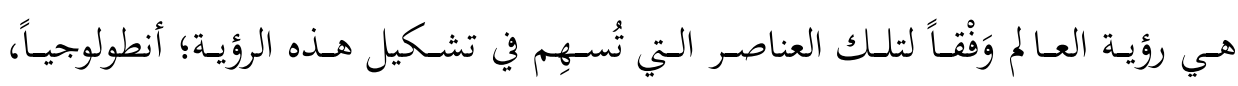
وإبستمولوجياً، وأكسيولوجياً.

والغاية من بسط هذه المنهجية هي التدرُّب على طرائق التفكير المنهجي، وتقرير أنه

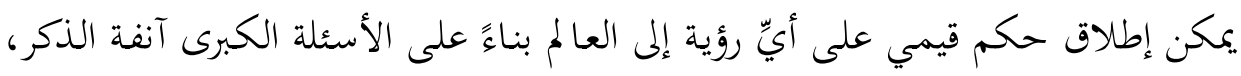

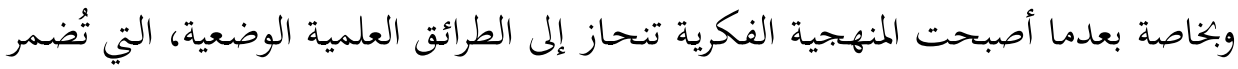

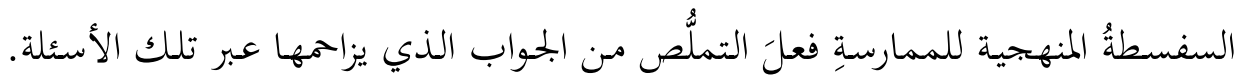

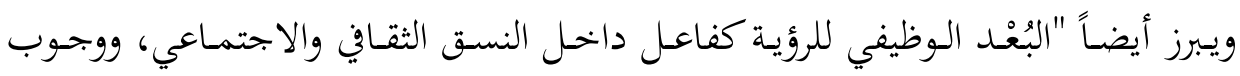

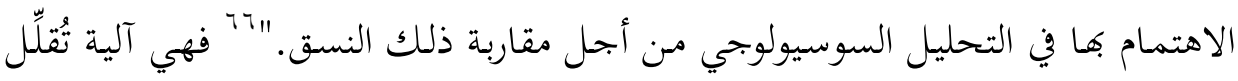

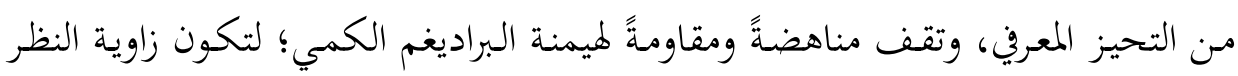

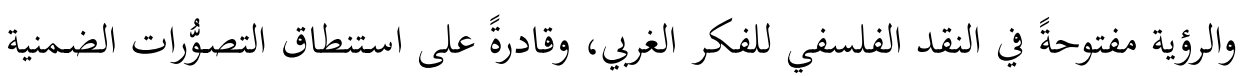

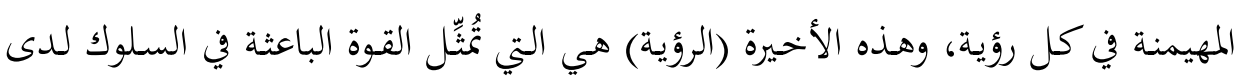

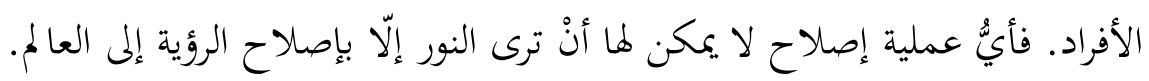

